Medievalia 24 (202I), II-5O - ISSN: 20I4-84Io (digital)

DOI: https://doi.org/I0.5565/rev/medievalia.545

\title{
JOAN DE RUA (MAESTRO DE CERVERA): UN PINTOR ARAGONÉS EN EL TALLER DE JOAN REIXAC
}

\author{
JOAN DE RUA (MASTER OF CERVERA): \\ AN ARAGONESE PAINTER \\ IN JOAN REIXAC'S WORKSHOP
}

\author{
Isidro Puig Sanchis \\ Universidad Politécnica de Valencia \\ ipuig@upv.es \\ https://orcid.org/o0oo-0002-638I-5579 \\ Miquel Àngel Herrero-Cortell \\ Universidad Politécnica de Valencia \\ mihercor@har.upv.es \\ https://orcid.org/o0oo-0002-3855-9542 \\ Joan Aliaga Morell \\ Universidad Politécnica de Valencia \\ jaliaga@har.upv.es \\ https://orcid.org/oooo-0002-4277-5790 \\ Ximo Company Climent \\ Universitat de Lleida \\ ximo.company@hahs.udl.cat \\ https://orcid.org/oooo-0002-8636-9823
}

Recepción: 22/04/202I - Aceptación: 10/07/202I

\section{Resumen}

La antigua personalidad artística del Maestro de Cervera, erróneamente identificado con Pere Girart, y al que se le atribuían toda una serie de pinturas en la órbita de Jacormart-Reixach, ha sido recientemente desvelada: Joan de Rua, aragonés. Ahora se presenta aquí un documento que nos permite confirmar una estancia 
formativa, que hasta ahora tan solo se le presuponía, en el taller de Joan Reixach. El presente artículo desgrana la relación entre Joan de Rua y Reixach y plantea una serie de reflexiones sobre su estilo y su técnica, para acabar proponiendo un somero borrador de obras que quizás deban atribuírsele.

\title{
Palabras clave
}

Pintura, Cataluña, Valencia, siglo xv, Joan de Rua, Maestro de Cervera, Joan Reixac

\begin{abstract}
Traditionally, the artistic personality of the unknown Master of Cervera, has been mistakenly identified with Pere Girart, and to whom a whole series of paintings in the orbit of Jacomart-Reixach were attributed. Its proper identification has recently been revealed: his name was Joan de Rua, from Aragon. Now a new document is presented here. It allows us to confirm a training stay that until now was only presupposed, in Joan Reixach's workshop. This paper describes the relationship between Joan de Rua and Reixach and presents some considerations on his style and technique, to end up proposing a brief draft of works that perhaps should be attributed to him.
\end{abstract}

\section{Keywords}

Painting, Catalonia, Valencia, Isth century, Joan de Rua, Master of Cervera, Joan Reixac

El sacerdote e historiador Joan Segura Valls daba a conocer en I895 una serie de noticias sobre la construcción de la ermita de San Miquel de Verdú (comarca de Urgell), en un paraje situado en los arrabales de la localidad. Se trata de un templo de planta rectangular, nave única apuntada, dividida en cuatro tramos con arcos torales y capillas entre los contrafuertes (Puig 2004, p. 23, doc. I).

La primera mención sobre su edificación es de I432, cuando Jaume Vilamartí deja en su testamento un florín a la obra de la iglesia de St. Miquel que sestá construint en lo terme de Verdú. En I 438 Pere Fulló ordenó que tras su fallecimiento fueran vendidos todos sus bienes y del llur preu sie obrada la església de sent Miquel. En 1442 otro legado testamentario se entregó para operarii operis ecclesie sancti Michaelis que nunc de nouo construitur. En I493 Antoni Capdevila contrató al maestro picapedrero Pere de Barba, de origen francés, para que pavimentase la ermita de San Miguel. 
Pero, sin duda, la noticia que nos interesa es la fechada el i6 de noviembre de I494, la única vinculada con el retablo de la ermita. Se trata del legado que hace en su testamento Llorenç Monçó: item deixo a la iglesia de Sant Miquel extramurs un flori d'or y XXIIII sous que havia promés pel retaule de dita iglesia y no'ls habia pagat y vull que sian pagats (Segura y Valls I895, pp. I54-I55). ${ }^{\mathrm{I}}$ En los términos en que está redactada esta voluntad del testador hemos de suponer que el retablo ya se había realizado y que todavía tenía pendiente entregar la cantidad que había prometido para costearlo. El retablo en cuestión no es otro que el Retablo de San Miguel que actualmente se conserva en el Museu Episcopal de Vic ${ }^{2}$ y que procede de dicha ermita de Verdú. La referencia cronológica en cuestión (I494) únicamente nos constata que en ese ańo el retablo ya estaba ejecutado.

\section{LA ENTRADA EN ESCENA DEL PINTOR PERE GIRARD Y EL MAESTRO DE CERVERA}

Salvador Sanpere i Miquel publicó en 1906 un contrato de mestre Pere Girard, pintor, natural de la ciutat de Valencia, habitant en la ciutat de Barchinona, fechado el I2 de noviembre de I479, con relación a la predela del retaule de la capella de Sant Miquel de la catedral de Vic. En el centro se representaría el Descendimiento de Cristo de la cruz, flanqueada por los compartimentos de la Resurrección y el Noli me tangere, y las puertas una con San Pedro y la otra con San Pablo (Sanpere y Miquel, 1906, doc. XVIII). ${ }^{3}$

Años más tarde, el canónigo de la Catedral de Valencia, D. José Sanchis Sivera, daba a conocer un documento con fecha del 2 de mayo de I490, por el cual Perot Girart pintor ciutadà de Valentia cobraba cierta deuda (Sanchis Sivera 1913, p. 58). A partir de este momento las noticias siempre le sitúan en Valencia.

La siguiente noticia en darse a conocer está datada el 8 de julio de I498, cuando la viuda de Gilardi Martell, depictoris quondam, Isabel, casada en segundas nupcias con el también fallecido Joan Gascó, notario, nombra procurador a su hijo, llamado igual que su padre y también pintor, Petrum Gilart, alias Martell, depictorum (Cerveró 1966, p. 22).

I Posiblemente, la equivalència del florín de oro en esa época y los sueldos mencionados llegarían casi a las 3 libras.

${ }^{2}$ Museu Episcopal de Vic. Inv. I768-I77I. Medidas 296,5 × 190,5 cm. Posiblemente debió ingresar en el MEV entre I892 y I893 a la par que el retablo del altar mayor de la Iglesia parroquial de Santa María de la misma localidad, obra del pintor leridano Jaume Ferrer II: Puig, 2004, pp. 98-IO3; Sureda, 2017, pp. 98-100.

${ }^{3}$ Archivo Episcopal de Vic, Curia Fumada, Manual de Juan Salles, I478-I48o, f. 208. 
Es el 28 de julio de 1489 cuando Pere Girart, alias Martell, pintor habitante en Valencia y hermano del fraile Joan Martell, presbítero beneficiado de la parroquia de San Esteban de la ciudad, actúa como testimonio de una deuda (Company I992, p. 433, nota 22). El I de octubre del mismo año, comparece de nuevo como testimonio del nombramiento de una procura. El 6 de febrero de I490, citado como Pere Martell, consta como testigo instrumental en una procura, y al mes siguiente, el 2 de marzo, nombra procurador a su hermano Joan, beneficiado (Company 2006a, p. 22I).

Posiblemente, el último de los documentos localizados sobre el pintor en cuestión es de los más interesantes, en cuanto a su naturaleza. Se trata del contrato de un retablo, fechado el 3I de enero de I489, entre la noble Violant de Centelles, monja del monasterio de la Zaidía de Valencia, y Girard para confeccionar un retablo en el que debe representarse en la tabla central la Resurrección; en el ático, la Virgen María de los Ángeles; en las tablas de la derecha san Lorenzo y, sobre ésta, el Martirio de san Lorenzo; en las tablas de la izquierda uno de los Gozos de la Virgen y arriba lo Goig de sent Martí; y en el banco, las figuras de san Bricio, san Clemente, el Ángel Custodio, el ángel Rafael, santa Elena, santa Bárbara, san Juan Evangelista, san Juan Bautista y santa Catalina. El retablo se debería realizar en dos años y el precio estipulado era de ioo libras (2.00o sueldos), a pagar en 4 años (Company et alii, 20I8, p. 477, doc. I5).

Parece ser que Pere Girard nunca llegó ejecutarlo, pues el 22 de octubre de I490 el pintor Martí Çamora contrata con la misma monja, Violant de Centelles, un retablo con la misma advocación, repitiendo prácticamente todas las capitulaciones, exceptuando algunos cambios. El precio ascendía de IOO a I25 libras. En esta ocasión el tiempo de ejecución coincidía con los plazos de pago, es decir, Martí debía pintarlo en dos años y medio y recibiría 25 libras cada medio año. Es igualmente interesante que, mientras que en el contrato de Girard se menciona que debía pintarlo con bones colors e fines, Martí, sin embargo, debía ejecutarlo al oli e de bones collors e fines. Por lo que respecta a la iconografía se realizan algunas modificaciones: la predela, tabla central y casi todos los santos del guardapolvos se mantienen (se sustituye la Santa Catalina por la Virgen del Rosario); como tabla cimera, en lugar de la Virgen de los Ángeles, ahora sería el Descendimiento, pasando aquella a la parte superior de la calle izquierda (sustituyendo, a su vez, al Goig de sent Martì); en lugar del martirio de San Lorenzo» aparece la Asunción de la Virgen; y el Gozo de la calle lateral deja paso a la imagen de San Martín (Sanchis Sivera, I913, p. 57).

Creemos que este cambio de autoría en el retablo que encarga la monja del monasterio de la Zaidía, Violant de Centelles, debería relacionarse con la información que nos brinda el documento del 8 de julio de I498, anteriormente citado, 
en el que Pere Girard consta como fallecido. La duda inmediata que nos aborda es ¿̨cuándo debió traspasar? A partir de ese documento (I498) podemos deducir que entre I490 (última referencia de Girard vivo) hasta éste de I498, su viuda, Isabel, había contraído matrimonio en segundas nupcias con el notario Joan Gascó, y éste también había fallecido, lo cual nos indica, o al menos es lo más lógico, que Pere Girard debía llevar unos años muerto. Es por ello que todo parece indicar, a modo de hipótesis, que el motivo por el que el pintor Martí Çamora se hiciera cargo del retablo de Violant de Centelles fuera el traspaso de Pere Girard, durante el mismo año I489 o al inicio del siguiente. La otra posibilidad, no descartable, es el incumplimiento del contrato o la imposibilidad de poder ejecutar, aunque hay que considerar que la pena por no terminarlo en el plazo pactado era la nada despreciable cantidad de 50 florines de oro por parte del pintor.

Anotadas todas las referencias documentales de Pere Girard podremos advertir que al no conservarse ninguna obra documentada del artista, y al no llegar a ejecutar el retablo de Violant de Centelles, no tenemos posibilidad alguna de conocer el estilo pictórico de Girard. A partir de las noticias de ese Girard valenciano, domiciliado en Barcelona, que pinta, por ejemplo, una predela para Vic en I479, el profesor norteamericano Chandler Rathfon Post propuso para un grupo de obras de influencia valenciana (en concreto del entorno de los pintores Reixac y Jacomart, datables en el último tercio del siglo xv, y ejecutadas en tierras catalanas) la autoría de Pere Girard, precisamente un pintor valenciano documentado e instalado en Barcelona, acunándolo de manera prudente como The Girard Master (Maestro Girard) (Post, 1938, VII, pp. 575-577). ${ }^{4}$ Otra opción valorada por Post era que tales obras fuesen del pintor valenciano Miguel Peris, también documentado en Barcelona en 1515 , pero que en 1490 sería todavía un aprendiz de Pablo de Montpeller (Sanpere y Miquel, 1906, pp. 202-203). En este sentido, la propuesta inicial de Post de identificarlas como obras de Pere Girard parecía, de hecho, la más plausible.

La obra capital que Post le atribuía a Girard era el mencionado Retablo de San Miguel, originario de Verdú (MEV, Fig. I. B). No obstante, reconocía que no existía ninguna conexión entre la documentación conocida de Pere Girard y las obras conservadas que se le pudiesen atribuir, circunstancia que todavía persiste hoy.

\footnotetext{
${ }^{4}$ Aunque hoy sabemos quien es el autor del Retablo de San Miguel de Verdú y que el grupo de obras que Post atribuyó al pintor Pere Girard se pueden depurar, creemos que hay que reconocer el mérito del profesor norteamericano, sobre todo siendo conscientes en qué momento escribió su obra y el conocimiento que de la pintura medieval se tenia en la década de los ańos treinta y cuarenta del siglo xx. Consideramos que no es justo quienes recuerdan incesantemente los «errores» de Post, menospreciando veladamente con fáciles juicios a quien tanto debemos.
} 
En 1987 Josep Gudiol y Santiago Alcolea consideraron que la propuesta de Post no podía sostenerse, esgrimiendo que Pere Girard se documentaba en Barcelona en I479 y que en I490 volvía a estar instalado en Valencia, de donde era oriundo. Esa cronología parecía no casar bien con la fecha propuesta para la ejecución del citado retablo de Verdú, hacia I494. Ante esta evidencia expresaron que era imposible atribuir ese grupo de obras, de clara raigambre valenciana, al pintor Pere Girard, acuńando para ello una nueva personalidad artística: la del denominado «Maestro de Cervera». La justificación de no etiquetarlo como «Maestro de Verdú» — que parecería más lógico a priori, por ser precisamente el retablo de San Miguel de esta localidad su mejor obra conocida-, era sencillamente para no incurrir en cierta confusión, dado que el propio Post ya había utilizado tal anónimo para referirse al autor del retablo mayor de la iglesia de Santa María de Verdú, obra del pintor leridano Jaume Ferrer II (Post, 1938, VII, pp. 513-524). Así fue bautizado como "Maestro de Cervera» (Gudiol - Alcolea, 1987, pp. 203-204), a raíz de unas tablas que formaban parte de un retablo procedente de la iglesia de San Juan de Cervera, dedicado a San Miguel Arcángel (Museu Comarcal de Cervera) (Balasch, 1995, pp. 38-48).

A partir de ese momento, 1987, la historiografía ha vacilado entre continuar atribuyendo ese grupo de obras — cuyo número iba variando-, a Pere Girard o bien considerar que su autor, siguiendo la propuesta de Gudiol y Alcolea, debía ser el ignoto «Maestro de Cervera». Lo cierto es que nada había seguro, y la ausencia de documentación alusiva a tales obras proyectaba una sombra de incertidumbre sobre su autor —al menos mientras perdurase tal circunstancia-, imposibilitando cualquier atribución en firme, tanto a favor Girard como a cualquier otro artífice identificado (Alcoy, 200I, pp. 53-56; Company, 2006a, pp. 220-22I; Velasco, 2002, p. 88). ${ }^{5}$ Paulatinamente la balanza se ha ido decantando a favor de mantener el anonimato del pintor, aceptando la antedicha figura del "Maestro de Cervera». Inexplicablemente, entre los argumentos esgrimidos para desatribuir el conjunto de obras a Girard, nunca aparecía ninguna referencia contrastable ni ninguna alusión sobre cómo pintaba (en términos estilísticos, formales y técnicos) el dicho Pere Girard, lo que se nos antoja verdaderamente importante, en primer lugar, para aceptarlo o descartarlo como autor (Velasco, 2002, pp. 63-88; y 20IO, pp. I33-I40). Rosa Alcoy subrayó, a propósito de los fondos dorados y la abundancia de estofados y pastillajes en la producción del Mestre Girard, que se explicarían a par-

5 Incluso Alberto Velasco señala sobre el autor de ese grupo de obras «per ara, continua essent suggerent la hipótesi de Post d'identificar-lo amb el valencià Pere Girard». 
tir de la influencia recibida en Catalunya — sin rehuir la aragonesa-, dado que había pintores que ejercían su profesión tanto en Catalunya como en localidades de Aragón, como acontecía, por ejemplo, con Pere García de Benabarre (Alcoy, I990, p. 190); unas valoraciones totalmente acertadas según nuestro criterio.

En la incesante búsqueda por encontrar un pintor con nombre y apellidos para identificar al citado «Maestro de Cervera» — pese a que la de Pere Girard parecía la personalidad más plausible_-, se pusieron sobre la mesa nombres como Pere Alegret, Joan García, Joan Brufau, Antoni Solanelles, un tal Francesc pintor de Tàrrega en I502, Miguel Garriga, Pere Algospí, Pau Vidal, Bernat de Medinacelli (natural de Xàtiva, Valencia) y Joan de Rua. Este último, se creía originario de Montblanc y en 1496 aparece policromando unos tabernáculos del panteón real de Poblet, noticia, con buen criterio insuficient per poder establir cap tipus de vincle ferm amb les obres atribuïdes al Mestre de Cervera (Velasco, 2010, pp. 98-IOo). Sin duda, ante tal elenco de propuestas era previsible que alguno de los antedichos acabase finalmente encarnando la disputada y misteriosa personalidad artística del arcano «Maestro de Cervera».

DESVELANDO LA INCÓGNITA: EL «MAESTRO DE CERVERA» IDENTIFICADO.

JOAN DE RUA (doc. I463-I496)

El hallazgo de Xavier Pont en 2015 en un manual del Archivo Parroquial de Verdú del contrato del Retablo de San Miguel (Museo Episcopal de Vic), fechado el is de septiembre de 1483 (Pont, 20I5, pp. 19-2I), acabaría por despejar las dudas sobre el desconocido artífice: el agraciado resultó ser Joan de Rua. Este descubrimiento deja, definitivamente, al pintor Pere Girard huérfano de obras, todas las que se le habían atribuido quedan adscritas así al pintor Joan de Rua, seguramente con taller en la localidad de Montblanc (Tarragona).

Así pues, el Retablo de San Miguel de Verdú adelanta su cronología. Si su única referencia cronológica era la deja testamentaria de I494, ahora su ejecución se avanzaba una década, ya que, según el contrato, debía realizarse entre septiembre de I 483 y febrero de I484, por un precio estipulado en 40 libras (véase Anexo documental 2).

${ }^{6}$ A partir de estas observaciones de Rosa Alcoy sobre la relevancia de los dorados y estofados, Ester Balasch extrajo como conclusión «que la via de penetració del pintor sigui aragonesa, sense descartar en principi la seva influència valenciana». Influencia valenciana que es, sin duda, la más destacable (Balasch, I993, p. 549), para después remarcar que era de «suposada procedencia aragonesa”, siempre a partir de las palabras de Rosa Alcoy (Balasch, 1995, p. 4I). 
Las medidas del retablo, sin el guardapolvos, son de $296,5 \times 190,5 \mathrm{~cm}$. Según el contrato debía tener de anchura 8 palmos de alna de Montblanc (aprox. unos 25,04 cm) por I2 palmos de altura. ${ }^{7}$ La invocación principal del retablo era la de Arcángel San Miguel y debían representarse otras devociones que estaban indicadas en la mostra que poseía el pintor, firmada por ambas partes. El abono de las citadas cuarenta libras debía realizarse en tres pagos. Una tercera parte al inicio de la obra, la segunda cuando estuviera preparado para dorar, y la tercera paga una vez estuviera concluido y colocado en la iglesia de San Miguel.

Estilísticamente se puede constatar, de forma inmediata, que se trata de un pintor que tuvo que estar en el entorno de Joan Reixac. Precisamente, la primera referencia que hasta hoy teníamos de Joan de Rua es la aparición como testigo instrumental en un ápoca de io libras a cargo del contrato concertado por Joan Reixac para la iglesia de Xàvea del 5 de septiembre de $\mathbf{4} 666$. El retablo estaba valorado en la nada despreciable cantidad de $\mathrm{I} 4 \mathrm{O}$ libras. Testimonios fueron Johannes Peres et Johannes de Rua pictores Valencie habitatores (Gómez-Ferrer, 20IO, p. 5I).

La siguiente referencia que quisiéramos citar es de octubre de I495, localizada en Cervera y que, tal vez, pudiéramos vincular también con Joan de Rua. En esta fecha el Consejo de la Paeria de Cervera encargó a los paers — junto con una comisión de prohombres-, que recaudaran fondos entre las cofradías y particulares con el fin de contribuir a pagar al pintor de Montblanc que iba a realizar el Retablo de la Almas del Purgatorio, del que, desafortunadamente, no se menciona su nombre (Verdés, 2003, p. 174). ${ }^{8}$

En 1496 Joan de Rua, como hemos mencionado anteriormente, se encontraba en el monasterio de Poblet, policromando los tabernáculos del panteón real, por encargo del escultor real Gil Morlanes, que realizó las tallas para las sepulturas de Juan II y Juana Enríquez (Espańol, I998-1999, p. 97), ${ }^{9}$ y consta que estaba domiciliado en Montblanc.

${ }^{7}$ Sobre esta medida, los palmos de alna de Montblanc, véase a Camps, 20Io, pp. 68-72. Este autor, a partir del retablo mayor del monasterio de Santa María de Poblet, calcula que el palmo de alna debía tener 20,8666 cm, pero aplicados al retablo de Verdú, no termina de cuadrar esta medida. Se conserva una vara de alna en el Museo Comarcal de la Conca de Barberà, cuyas medidas son $125,2 \mathrm{~cm}$.

${ }^{8}$ Archivo Histórico Comarcal de Cervera, Fondo Municipal, Consells, I495, f. 86 r., 2I/Io/ I495.

9 El documento en cuestión se encuentra en el Archivo Diocesano de Girona, ms. I4, fol. 9ov.: «I496 fonch feta avinença entre mestre Gil Morlan de Çaragosa imaginayre del Sr. rey e mestre Juan de Rua pintor de Muntblanch, çoes que mestre Joan aja de pintar los tres tabernacles de les tombes reals de la banda del cor de (l')abat y que ell mateix se faxa la despesa y se cerque or, colors e obre, y lo dit mestre Gilli done norante lliuras. Consta en lo manual de fra Pere Davins monje y notari de Poblet. Llavors se feya la tomba del rey en Joan II segons consta apocha de dit preu». 
Es muy probable que el pintor Jeroni de Rua, que aparece también domiciliado en Montblanc, sea precisamente el hijo de Joan. Jeroni de Rua, consta el Is de enero de I54I contratando el Retablo de la Virgen de la Iglesia de Santa María de la Guàrdia Lada (Montoliu de Segarra), junto con el fraile mercedario Gil, pintor de origen flamenco y conventual en Agramunt (Duran y Sanpere, I933, pp. 265-270). ${ }^{\mathrm{IO}}$ Los capítulos pactados con los jurados de la mencionada localidad son muy precisos, tanto en iconografía como en los colores utilizados para cada prenda y personaje.

JOAN DE RUA, DISCÍPULO DE JOAN REIXAC

Desde que se diera a conocer el Retablo de San Miguel de Verdú, una de las características más sobresalientes y llamativas era su fuerte conexión con el mundo pictórico levantino. Independientemente de la autoría propuesta para este conjunto (Pere Girard, The Girard Master, Mestre de Cervera), estaba claro que su autor debía haber conocido de primera mano el panorama pictórico valenciano de los años centrales del siglo xv y, en concreto, a los dos pintores mejor documentados e influyentes: Joan Reixac (c. I4II - h. I484) y Jaume Baçó (alias Jacomart, h. I4II I46I). Todos los estudiosos que han tratado este conjunto de obras han advertido esta dependencia.

En todo caso destacamos algunos como Post que observó que un elevado número de obras catalanas podían adscribirse a one of Jacomart's and Rexach's followers; mientras que Josep Gudiol y Santiago Alcolea hablaban de «un modest pintor format a València» (Gudiol - Alcolea, 1987, p. 203), o Ximo Company que señalaba que el retablo era obra d'un deixeble de Jacomart-Reixac (Company, I992, p. 432).

La mencionada noticia de I466, en la que Joan de Rua figura como testigo de un pago a Reixac por el retablo de Xàvea, no hace más que evidenciar esta relación. Un pintor que había conocido de primera mano a uno de los artífices más relevantes del panorama artístico del cuatrocientos levantino.

En esta misma línea, y para redondear más, si cabe, esta vinculación Rua Reixac, estamos en condiciones de constatar documentalmente que Rua se formó con el pintor Joan Reixac, como permitían sospechar sus débitos estilísticos y

10 Uno de los testigos del contrato es el "venerabilis Ioannes Rua, presbiter», de Montblanc. Es posible que tuviera alguna relación familiar con el pintor Jeroni Rua que, en tal caso, por la cronología, pudiera tratarse de un hermano o un hijo. En la localidad leridana de Agramunt se fundó el convento de mercedarios, hacia I3I2. 
formales. El documento localizado, fechado el i8 de julio de I463, en Valencia, a pesar de ser breve, nos aporta una valiosa información. Se trata de una suerte de contrato de formación de Joan de Rua con el pintor Joan Reixac. El pliego presenta unas interesantes particularidades si se compara con los habituales contratos de aprendizaje. En ese momento de Rua declara que era mayor de veinte años — seguramente no tendría muchos más_-, y que era oriundo de la ciudad de Zaragoza. El documento da a entender que Rua solicita a Reixac que le acepte como discípulo para entrar a su servicio en el taller, realizando cualquier tarea que le ordenase. Joan de Rua se comprometía a pagar a Reixac cada año is sueldos para acceder a su taller y formarse con él. A cambio, Reixac se responsabilizaba de su manutención, es decir, alimentarle y revisar anualmente el estado de su ropa y zapatos. Así mismo, por cada día que Rua no cumpliese con sus tareas por enfermedad, lo supliría con otros dos días de trabajo. Se trata de cláusulas muy favorables para Reixac, que se compromete a aceptarlo durante tres años -que habían empezado a contar a partir del I de mayo del mes anterior-, por lo tanto el acuerdo se alargaba hasta el 30 de abril de I466. Este descuadre temporal puede entenderse como un cierto tiempo en que debió tenerlo a prueba, para ver si realmente le era útil y si tenía cualidades (Anexo documental I).

Dentro de la valoración de los contratos de aprendizaje podemos encontrar cierta heterogeneidad en la duración de estos, en la edad del aprendiz y en la posible remuneración final. En el caso que nos ocupa el contrato es de poca duración, en la que el discípulo, Joan de Rua, es ya un joven de poco más de veinte. Si fuera un aprendiz que inicia su formación, un nińo de entre diez y catorce ańos, el contrato tendría una duración media entre seis y ocho años. Además, no se introducen en las capitulaciones los verbos addiscere ni docere, que son uno de los rasgos que nos ayudarían a identificar este tipo de vinculaciones de jóvenes que acceden a aprender el oficio de inicio, sino que encontramos los términos discipulum et servicialem vestrum, es decir, que entra en el taller como discípulo y al servicio del maestro.

Por todo lo expresado, y por la edad de Joan de Rua, es posible que ya hubiera terminado su aprendizaje en otro taller, quizá con algún pintor zaragozano, y que se trasladara a Valencia a completar, consolidar y perfeccionar su formación, como un oficial colaborador, ni más ni menos que en el taller más importante de la Valencia del momento - y tal vez de la Corona de Aragón—, pues recordemos que Jacomart había fallecido el i7 de julio de I46I (Tormo, I9I3, pp. II6-II9).

II Sobre los contratos de aprendizaje o «d'afermament» véase, por ejemplo: Fernández Somoza 1997, Miquel, 2008, pp. I66-173, Montero, 2013, pp. 2I-3I y Fernández Somoza 20I6, pp. I9I-208. 
El caso de Joan de Rua no es el primero con estas características. Trazando un paralelo razonable, el 22 de junio de 1448 Jacomart había aceptado como aprendiz/discípulo a Jaume Vergos (II) (c. I424 - I503), hijo de Jaume Vergós (I), pintor de Barcelona (Gómez-Ferrer, 1994, p. 22). ${ }^{\text {I2 }}$ El tiempo estipulado eran también 3 años, e igualmente tenía más de 20 años, seguramente unos 24 (Molina, 2006, pp. I22-I3I). El documento, como en el caso de Joan de Rua, no indica que Vergós fuera pintor, aunque por la edad, de nuevo, ya habría completado una primera etapa de formación con su padre en Barcelona.

Estos contratos con pintores levantinos no hacen más que reafirmar el papel puntero que tenía el puerto valenciano, como receptor y difusor de las novedades pictóricas que llegaban a la corona catalanoaragonesa a la mitad del cuatrocientos. De hecho, las novedades que llegan a Barcelona a partir de la década de los años cuarenta vienen de las manos de pintores como Lluís Dalmau (GómezFerrer, 2018, pp. 5-18), Jaume Huguet (Ferrer Puerto, 2003, pp. 27-32) o Miquel Nadal (Alanyà, 2015, pp. 345-360).

PRODUCCIÓN PICTÓRICA DEL TALLER DE REIXAC DURANTE LA ESTANCIA

DE JOAN DE RUA

Durante el periodo en que Joan de Rua estuvo trabajando en el taller de Rei= xac, se tienen documentadas algunas obras del maestro. Una de ellas, en la que posiblemente pudo trabajar el aragonés, es el retablo de la nueva capilla real en el

${ }^{12}$ El documento completo transcrito es el siguiente: «Predictis die sabbati, XXIIa iunii et anno a Nativitate Domini MCCCCoXXXXVIIIo. / Iacobus Vergós, filius Iacobi Vergós, pictoris civis Barchinone, gratis et cetera, asserens me fore maiorem viginti annis, affirmo me ipsum vobiscum Iacobo Bacó, pictore, cive civitatis Valencie, presente et acceptante, ad tempus [tri] um annorum proxime venturorum et continue computandorum ad officium pictoris, promitto et cetera, vobis et domui vestre servire per dictum tempus trium annorum in dicto officio bene et fideliter et cetera, et a domo et servicio vestris per dictum tempus non recedere. Quod si facerim, possitis vestra propria auctoritate sive licencia alienus iudicis et officialis me capere et capi facere et in vestri servicium redire tantum et tandiu donec temporis let/ deffecti emendam fecero integralem, dum tam durante tempore dictorum trium annorum michi provideatis in potu, vestitu et calciatu, prout in similibus Valencie est assuetum et doceatis [in] dictum vestrum officium seu artem pictandi iuxta posse [...] et cetera, me et bona mea et cetera. Ad hec ego, Iacobus Bacho, predictus, presens et acceptans, vos, dictum Iacubum Vergós, in famulum meum ad tempus predictum trium annorum, promitto vobis, presenti et acceptanti, vos docere dictum officium seu artem pictoris iuxta posse et omnia alia et singula per me attendenda et cetera, attendens et cetera obligo et cetera. Actum Valencie et cetera./ Testes, Iacobus d'Aliaga, panni parator, et Ludovicus Rodriguez, sartor Valencie». 
monasterio de Santo Domingo de la ciudad, cuyo primer pago se abonó a Reixac el 6 de julio de I463 (I.833 sueldos), lo que indica que el contrato haría poco tiempo que se habría formalizado (Sanchis Sivera, 1930, p. 154). En cualquier caso, en la fecha, Joan de Rua hacía dos meses que se había incorporado al taller. De hecho, los cobros se alargan, al menos hasta I468, cuando Joan Reixac recibe I.500 sueldos del maestro racional a cuenta de los 5.500 sueldos pactados por la realización del retablo de la capilla real del monasterio de Santo Domingo de Valencia (Framis - Tolosa, 1996, p. 43I).

Durante el año 1465 constan una serie de pagos a Reixac por la pintura de las puertas del órgano de la Catedral (Sanchis Sivera, 1909, p. 54I). El ro de junio de dicha anualidad, Jaume Beneyto, secretario del rey y escribano del consejo de la ciudad de Valencia, encargaba a Reixac el Retablo de la Encarnación de la capilla de la iglesia de San Nicolás, que debía entregar antes de la festividad de Todos los Santos. En caso de no concluirlo a tiempo, debería devolver todo lo que hubiera recibido y el propio retablo de madera inacabado. Finalmente, parece que debió cumplir con el encargo, pues el in de abril de I466 Reixac firmaba a Jaume Beneyto una ápoca de I.300 sueldos por el retablo en cuestión (Corbalán, 2003, p. 192).

Habría que ańadir a esta lista el retablo de la iglesia parroquial de Xàvea, del que solo conocemos la apoca — citada anteriormente- del 5 de septiembre de I466, que habría contratado unos meses antes — quizá en 1465 - y en la que a buen seguro trabajó Joan de Rua. Si nos detenemos en la fecha del ápoca, advertiremos que el período de aprendizaje de Rua habría concluido unos cuatro meses antes, el 30 de abril. Deberíamos, pues, considerar que un activo taller como el de Reixac necesitaba constante mano de obra, dado el elevado volumen de encargos y trabajos varios recibidos, lo que podría explicar la continuidad de Joan de Rua, tal vez con otro tipo de contrato, en esta ocasión como oficial. Sería el caso, por ejemplo, de uno de estos oficiales o colaboradores que formaron parte del activo taller de Reixac: el pintor Joan Pérez, quien precisamente figura en el contrato de aprendizaje de 1463 del mismo Joan de Rua como testigo. ${ }^{\text {I3 }}$

${ }^{13}$ Precisamente, ambos comparecerán también como testimonios en el mencionado pago del retablo de Xàvea en I466. Esta estrecha relación Reixac - Pérez la constatamos desde que juntos se presentaron como testigos en el testamento de Gonçal Peris Sarrià, del 23 de septiembre de I45I (Sanchis Sivera, I929, p. 48). Esta vinculación perdura documentalmente al menos hasta I486. El 3 de abril de 1470 Joan Pérez es testigo en un ápoca firmada por Reixac como pago por el retablo de San Pedro de la catedral (Sanchis Sivera, I909, p. 54I). El I3 de agosto de ese mismo año de nuevo en una venta (ACV, Protocolo de Joan Esteve, n. 368I). El 24 de septiembre de I47I comparece Reixac como de albacea y ejecutor del último testamento de Caterina Roca, viuda de Pere Roca, 
En años inmediatamente sucesivos llegarían dos encargos importantes y que, por las obras que ahora le podemos atribuir a Rua en Catalunya, debió de conocer de primerísima mano, habida cuenta de los préstamos formales presentes en las mismas. Nos referimos, en primer lugar, al Retablo de Santa Úrsula y las once mil virgenes, para la capilla homónima la de la iglesia del monasterio de Santa María de Poblet (desde I922 en el MNAC), firmado en el año I468 (Beserán Alcoy, 1994, pp. I45-I50). Por el tamaño del conjunto, coste y tiempo necesario para su ejecución, pudo haberse contratado unos dos ańos antes, tal vez I466. De aceptar esta fecha de encargo, Joan de Rua podría haber participado en su ejecución. En segundo lugar, el otro gran conjunto de importancia capital es el Retablo de la Epifanía, procedente del Convento de Agustinas de Rubielos de Mora, desde mediados del siglo xx también en el Museu Nacional d'Art de Catalunya. La cronología que se maneja actualmente para esta obra es de hacia I469 (Montolío - Igual, 2000, p. 32). Todo parece indicar que Joan de Rua continuó en Valencia unos años más, pues es casi seguro que debió conocer este conjunto, dado que hay escenas que pudieron inspirarle en representaciones posteriores, como el Retablo de la Virgen del Lirio de Vilanova de Bellpuig (Urgell, Fig. 2. B) (Velasco, 2002, pp. 63-88).

Hay una serie de escenas de este retablo de Vilanova cuya composición está inspirada en las homónimas del conjunto de Rubielos, como la Adoración de los Reyes (Fig. 3. A y B), Anunciación (Fig. 3. E y F), Nacimiento (Fig. 3. G y H), Resurrección (Fig. 4. A y B), Ascensión (Fig. 4. F y G), Pentecostés (Fig. 4. H e I) y Dormición (Fig. 5. A y B) que, además, también tiene su similitud con la procedente de la cartuja de Portaceli (Museo de Bellas Artes de Valencia, inv. 2II, Fig. 5. C). ${ }^{\text {I4 }}$

mercader de Valencia, y Joan Pérez consta de nuevo como testigo: magister Iohannes Pérez, pictor, Valencie vicinus (documento reseñado, pero no transcrito, en Corbalán, 2003, pp. 192-193). Y por último, Joan Reixac se menciona el 8 de agosto de I486, cuando una tal Úrsula, viuda del antedicho pintor Joan Pérez, de Valencia, vende a Andrés Nadal un trozo de tierra de unas dieciséis fanegadas, en la partida de Cabañal, por el precio de treinta y cinco libras (Cerveró, 1963, p. 155). No obstante, según la documentación conocida, parece que en la misma centuria convivieron en Valencia varios pintores con el mismo nombre e incluso el apellido «Rexach» parece repetirse entre artífices, lo que dificulta separar las respectivas personalidades, cuya posible relación no está todavía clara, pudiendo incluso tratarse de una saga. Un tal Pere Rexach, pintor, por ejemplo, aparece acometiendo nada más y nada menos que las pinturas murales de la Capilla Mayor de la Catedral de Valencia en I47I, tras el incendio de 1469 (Libro de fábrica, núm. I.506 F, del Archivo Capitular de Valencia).

${ }^{14}$ Estas relaciones compositivas entre el retablo de Vilanova de Bellpuig y el de Rubielos ya fueron advertidas por: Ferre Puerto, 1997, p. 317. En cuanto a la suposición planteada por Josep Ferre sobre que el retablo de San Miquel de Verdú estuviera inspirado en el de Burjassot de Reixac, consideramos que es arriesgado afirmarlo, pues no se conoce, para nada, la composición del retablo 
En el caso del San Miquel titular del retablo de Verdú consideramos que tiene una relación más directa con el representado en la calle lateral del conjunto de Rubielos (Fig. 6. A y B) que con el conservado en la Galleria Parmeggiari (Reggio Emilia, tal vez procedente de Burjassot, Fig. 6. C). Tanto en el de Verdú como en el de Rubielos aparece el demonio en los pies, de color verde; los escudos presentan la misma cruz roja e idénticos reflejos metálicos; o los forros de las respectivas capas son de color púrpura, quedando únicamente alterada esta similitud con la postura de los pies. En cuanto a la tabla central del mueble de Vilanova, con el tema de la Virgen y el Niño, encuentra su modelo en la que aparece sobre la Santa Úrsula del retablo del MNAC, procedente de Poblet, aunque sin los ángeles ni donante (Fig. 4. C y D).

En otras obras de Joan de Rua también utiliza los referentes de Reixac, como en el retablo de Verdú. Si se compara el Cristo Varón de Dolores de la predela con el de Rubielos, en ambos casos Cristo cruza los brazos (Fig. 7. A y B). Tal confrontación es igualmente efectiva, por ejemplo, para la Santa Lucía de Verdú, con la santa análoga de la predela del Retablo de San Lorenzo y San Pedro de Verona de Catí (c. I46I), que difieren cambiando de manos los atributos (Fig. 7. C y D). El San Pedro de Joan de Rua que se conserva en el Museu Diocesà i Comarcal de Solsona, tiene su referente, de nuevo, en el de Rexach para la Iglesia Arciprestal de Santa María la Mayor de Morella (hoy en su museo, Fig. 8. C y D), aunque el pintor hace modificaciones en la indumentaria del santo, fundamentalmente para ańadir más motivos decorativos en dorados y «estofados», observándose unos mismos elementos geométricos en ambos tronos. Otra obra conservada en la Auckland Art Gallery (Nueva Zelanda), con Santa Ana, la Virgen y el Niño, retoma el modelo de esta iconografía que se encuentra en una de las calles laterales principales del retablo de Rubielos (Fig. 4. E y J). En el caso de las escenas conservadas del Retablo del Ángel Custodio, de Santa María de Cervera (Museu Comarcal de Cervera), la Anunciación y Nacimiento, Joan de Rua toma de nuevo su referente en el mueble de Rubielos (Fig. I. A; compárese con Fig. 3. F y G); mientras que para el Varón de Dolores se inspira, de nuevo, en el del Retablo de Santa Úrsula (MNAC), donde Cristo deja caer totalmente sus brazos y mantiene los puños cerrados. Lo mismo ocurre con la Epifanía del Museu Episcopal de Vic (Fig. 3. C) y la de una colección particular de Verona (Fig. 3. D) (Limentari,

de Burjassot. Además, Rua debió ver el de Rubielos, que se ejecutó mientras estaba en Valencia, pero el de Burjassot hacía años que se había realizado (c. I444) y seguramente no llegó a conocerlo. 
200I, p. 29, fig. 29), muy parecidas, que mantienen básicamente la composición de Rubielos (Fig. 3. B).

En realidad, en todos los casos, las copias que realiza Joan de Rua de las composiciones de Reixac no son literales, sino adaptadas, tomando de ellas lo esencial, según sus pretensiones, incorporando ciertas variaciones. El pintor no desdeña ligeros cambios de poses, gestos, objetos, diseño de la indumentaria y otros aspectos relativamente triviales. Como característica de su factura, utiliza, en lugar de los típicos nimbos disciformes repicados, nimbos y cenefas doradas ejecutados con la técnica del pastillaje (embotit), tan distintiva de los pintores aragoneses — aunque también se empleaba ampliamente en Cataluña-. Se trata, seguramente, de un recurso heredado de su formación inicial aragonesa que debió recuperar tras su asentamiento en Montblanc, muy del gusto de la época en aquellas latitudes, como puede apreciarse en la tabla de San Pedro de Solsona.

Si retomamos los posibles referentes directos que Rua pudo observar en el taller de Reixac, tal vez podamos considerar que, unos meses antes de iniciar el retablo de Rubielos de Mora, Reixac se había comprometido con una nueva obra. El 2I de abril de 1469 el pintor pactaba con los albaceas testamentarios del fallecido Antoni Bou, canónigo de la catedral de Valencia, la ejecución de un retablo bajo la invocación de San Pedro, para la capilla de homónima advocación en la catedral (Sanchis Sivera, 1909, pp. 28I-282). El precio acordado eran 2.000 sueldos (Ioo libras), más otros 600 sueldos (30 libras) si lo acaba antes de la festividad del santo de I470 (29 de junio). Esto suponía que los trabajos debían acelerarse para concluirlo en catorce meses, con la dedicación que ello requería por parte de otros colaboradores. A tenor de este incentivo por su pronta ejecución, recordemos que en el citado Retablo de la Encarnación también se instó al pintor a no retrasar su entrega, estipulada en el contrato. Finalmente, el retablo de San Pedro se debió entregar a tiempo, pero no del todo a gusto de los albaceas de Antonio Bou, pues hubo al respecto una aquerella contra Reixac, debido a que consideraban que «en lo dit retaule hi hauria molts deffectes e no sería stat acabat ab aquella perfectió e acabament». En la sentencia arbitral dictada el juez, tras escuchar las alegaciones de ambas partes, obliga a Reixac a realizar algunos cambios o reparaciones. En la tabla central de San Pedro «reparar la dita ymatge, axí en la testa com en la longaria del vestit, y en la predela endolcir les testes de nostre Senyor de la Resurrecció e reglaçar alguns vestits ab color de oli de aquella color conforme a la color que és a coneguda de mi». El juez, además, imponía a los albaceas el pago de la totalidad del precio del retablo, los 2.000 sueldos, más 300 sueldos por el oro gastado por el pintor en las reparaciones. Todo parece indicar que los «errores» cometidos se debieron a la premura por concluir la obra y, muy probablemente, a la interven- 
ción de sus colaboradores, incurriendo estos en ciertas «imperfecciones» (Nicolau Bauzà, 1985, p. 35; Corbalán, 2003, pp. 19I-192).

Estos retrasos en la entrega y premuras en las hechuras de las obras debieron ser algo habituales en el taller de Reixac. Tenemos, al menos, otro caso documentado en el que concurren análogas circunstancias: el retablo para la iglesia parroquial de Museros. Fue inicialmente contratado con el pintor Jacomart, el i7 de marzo de 1450 (Gómez-Ferrer, 1994, pp. 23-24). Por razones que se desconocen, el retablo quedó inacabado, ya que, tras su muerte, el I9 de noviembre de I46I, fue contratada su conclusión con Joan Reixac. Se menciona en las capitulaciones que tenía dos años y medio para concluirlo, por una suma de 2.400 sueldos. El pintor recibiría el retablo ya entallado en madera y dorado, salvo por la punta y la base, y tenía que pintar la imagen de la Virgen María con Jesús en brazos y ángeles en la tabla principal, el Crucifijo en la espiga, y los seis Gozos de la Virgen en las escenas laterales. Tendría, además, que realzar y pintar los guardapolvos, donde ha de aparecer las armas de San Jaime de la Espada; y en la predela pintar las seis historias de la Pasión. ${ }^{15}$ Debería haberlo concluido en mayo de I464, (de nuevo Joan de Rua estaba entonces trabajando con Reixac). Lo cierto es que hubo nuevos retrasos, de momento injustificados, por lo que la villa de Museros hizo una concordia con el pintor, del I6 de agosto de I470, en la que Reixac se comprometía a acabar todo el conjunto en el plazo de un año, es decir, entregarlo antes del is de agosto de I47I. No obstante, antes de la Navidad de I470, debería presentar las tablas laterales con los Gozos («que de ací a la vespra de Nadal primervinent darà les dues taules de costats en que són los Quatre Goigs acabades a la dita universitat») (Cerveró, 1972, p. 50). Prácticamente son diez años de retraso que no podemos explicar, y no parece que la causa proceda de la parte contratante. Más bien nos inclinamos a pensar en una gran acumulación de obras y encargos que colapsaron el taller de Reixac durante la década de los años sesenta, y que, al menos, durante esos años, motivarían una cierta ralentización del trabajo. Es en este momento cuando más se justifica la necesaria implicación de un pintor como Joan de Rua que, aunque poco conocido y tachado por algunos como mediocre, creemos que constituye un excelente paradigma de lo habituales que fueron las colaboraciones

Is «Primo, és tengut lo dit en Francesch Rexach pintar acabadament e daurar d'or fi lo dit retaule, lo qual de fusta li donen e liuren ja acabat per son punt exceptat, que no és tengut daurar lo tabernacle del dit retaule baix hon ha éstar lo cors de Jesuschrist, lo qual té ja lo dit loch, fet e daurat, és ver que és tengut daurar e acabar cert peu o enbassament que se-s haud a fer per al dit tabernacle, e tot l'àls ha e és tengut a fer e acabar segons que.s pertany, e donar lo acabat ab ses polseres e banchs de ací a dos anys e mig primer vinents e continuament comptant, totes excepcions a part possades»: Gómez-Ferrer - Corbalán, 2003, pp. 2I-24. 
de artífices en la sombra (aprendices, oficiales, y maestros asalariados); pintores cercanos que asimilarían el arte de Reixac con cierta dignidad, emulando sus composiciones y sus facturas, con análogos recursos plásticos y técnicos.

La lista de obras que habría visto Joan de Rua en el taller de Reixac se podría ir alargando, pero lo cierto es que desconocemos, a falta de más noticias que vayan saliendo a la luz, hasta cuándo pudo permanecer en el taller de Reixac. Sus pinturas y la profunda asimilación del estilo del maestro nos hacen pensar que fue una temporada importante; un lustro, como mínimo. La siguiente noticia de Rua es el conocido retablo de Verdú, contratado en I483, lo que deja todavía un lapso documental de unos is años desde su última noticia de Valencia y esta de Verdú.

No podemos dejar pasar por alto otro dato llamativo. Después de trabajar con Reixac en Valencia lo encontramos domiciliado y con taller en Montblanc, que curiosamente dista poco más de io kilómetros del Monasterio de Poblet, lugar de destino del Retablo de Santa Úrsula. Sería razonable, como hipótesis, que Joan de Rua tras ayudar a la colocación del retablo en el cenobio pobletano, en I468, decidiera instalarse en solitario por alguna localidad cercana, como lo era Montblanc, pues, así como a Joan Pérez se le sigue documentando hasta I47I, siempre vinculado a Reixac, en el caso de Joan de Rua, en Valencia se pierde su rastro tras su testimonio de 1466.

ALGUNAS CONSIDERACIONES TÉCNICAS SOBRE LAS PINTURAS DE JOAN DE RUA, SUS MATERIALES Y SU LENGUAJE PLÁSTICO Y PROCEDIMENTAL

Desde la década de 1460 el óleo va erigiéndose en Valencia - y, en menor medida, en otras partes de la Corona de Aragón- como un procedimiento que sumaba cada vez más adeptos, si bien su asimilación fue un proceso que conllevó varias décadas. Por aquel entonces coexistían dos grandes facciones técnicas: la de los pintores más veteranos y retardatarios, que todavía preferían y usaban íntegramente la témpera, siguiendo los viejos preceptos de los lenguajes técnicos del Gótico Internacional; y el grupo de los que comenzaban a abrirse hacia las novedades técnicas que implicaba la adición del aceite a sus pocillos, utilizando la incipiente técnica del óleo — aunque muchas veces fuese tan sólo para las veladuras finales- juntamente con diversos tipos de temple de huevo y cola. ${ }^{16}$

${ }^{16}$ Una aproximación al panorama técnico del Reino de Valencia en lo que a la adopción del óleo se refiere en: Herrero-Cortell (2019, pp. 702-708 y 730-75I). 
Conviene recordar, para contextualizar tal afirmación, que son pocos los contratos que en esas fechas especifican en sus cláusulas el uso del óleo como aglutinante. Ello no entra en contradicción con el hecho de que el médium ya gozase de cierta dispersión, por más que fuese siempre juntamente con otros aglutinantes de la familia de las témperas, como se ha dicho. Prácticamente, los términos contractuales que estipulan obligatoriamente el uso del óleo — salvo alguna excepción puntual-, no comienzan a popularizarse hasta I485, como constata un significativo incremento de casos como ciertos contratos de Martí Zamora, Pere Cabanes, o Martí Torner, (Sanchis Sivera, 1930, pp. 202-205, 2010-2II) aunque en la práctica, dicho uso del óleo siga siendo, con frecuencia, sobre las mencionadas bases al temple. Se trata de un fenómeno análogo en toda la Corona de Aragón: valga recordar el antedicho caso del retablo que Martí Zamora contrata con Violant de Centelles en I490, para dar cumplimiento a un encargo previamente realizado a Pere Girard y en el que, a diferencia de lo que había acontecido en las capitulaciones de Girard, se exige ya como cláusula que sea al oli (Sanchis Sivera, I9I3, p. 57).

Pero tal adopción no fue, ni mucho menos, inmediata pues no es ya hasta superado el horizonte del 1500 cuando el hecho de solicitar como condición que la pintura se realice al óleo parece una estipulación común, incluso a veces indicando expresamente que no se utilice en ningún caso el temple, lo que desde nuestro punto de vista supone una constatación de la pervivencia en las anteriores décadas de la témpera, aunque fuese en forma técnica mixta. ${ }^{17}$ Ciertamente, desde la irrupción de las nuevas metodologías importadas por Lluis Dalmau — que hacia mediados de siglo se encontraba de nuevo en Valencia- (Gómez-Ferrer, 20I8), la experimentación del aceite diluye la frontera entre témpera y óleo en una suerte de técnica mixta (témpera grasa), si bien, pocos, como Dalmau debieron conocer los entresijos y vericuetos técnicos de un procedimiento que, lógicamente, en Valencia no gozaba de tradición. Representantes de esta tendencia experimental con el uso de aceites y resinas — fruto de la voluntad de mímesis con los lenguajes flamencos- son precisamente Rexac y Jacomart, como también el llamado «Maestro de Segorbe», el «Maestro de la Porciúncula» o Bertomeu Baró, por mencionar

${ }^{17}$ Es interesante, por ejemplo, prestar atención al contrato de Paolo da San Leocadio del 29 de noviembre de I50I, suscrito con Dońa María Enríquez para la pintura del Altar Mayor de la Seu Colegiata de Gandia, en el que se obliga al italiano a que pinte exclusivamente al óleo. El contrato en cuestión estipula: «que lo dit mestre Paulo de Sant Locadio sia tengut e obligat de pintar lo sobredit retaule [...] a l'oli e no trempre e tot son càrrech e despesa en la vila de Gandia" (Company, 2006b, p. 470). 
tan solo algunos nombres; pintores en cuyas obras se hace difícil atisbar las partes netamente ejecutadas con uno u otro procedimiento. En este mismo grupo de artífices se encuentra también Joan de Rua, desplegando un modesto abanico de recursos plásticos que tratan de emular soluciones procedimentales propias de los lenguajes flamencos, sin renunciar, al mismo tiempo, a otras algo más arcaicas.

Quizás sea operativo, para entender el uso que del aglutinante oleoso hacían tanto Reixac — como de Rua - atender a algunos de los contratos. Por ejemplo, la apoca del retablo ejecutado por Joan Reixac para el Monasterio de Santo Domingo, datado en I463, especifica que tal pago es "per pintar e acabar be e abtament de colors al oli lo retaule de la dita Capella» (Sanchis Sivera, I930, p. I54). Apenas tres ańos más tarde, en otra ápoca, en este caso de unas piezas de caballería para el rey Juan II, Reixac admite que «me son estats tatchats axi per enguixar e aparellar de guix prim unes cobertes de cavall, les quals lo dit Senyor Rey vos trames per mossèn Rocamora per que aquelles faessets pintar, guarnir e acabar al oli obtament» (Sanchis Sivera, 1930, pp. 155-156). Atendiendo a ambas afirmaciones se colige que el uso del óleo constituía un acabado, más que el aglutinante único de la pintura. $\mathrm{Y}$ esto mismo puede deducirse de diversas analíticas e informes de conservación alusivos a piezas tanto de Reixac como de Jacomart (Herrero-Cortell, 20I9, pp. 746-75I), aunque en general, son muy escasos los análisis químicos realizados a obras del periodo como para tratar de entender metodológicamente qué preceptos técnicos y procedimientos constituían sus metodologías de trabajo.

Una visión cercana de obras como el San Miguel de Verdú, (Museu Episcopal de Vic), revela una cierta continuación de estilemas y hechuras que, más allá de los antedichos débitos directos para con obras de Reixach, ya se habían visto durante la década anterior en Valencia. Por ejemplo, el uso de corlas diversas para dibujar con trazos oblicuos sobre la armadura, totalmente cubierta de hoja de estaño, plata y oro, es un recurso propio del Gótico Internacional. También lo es el tratteggio —en ocasiones algo duro-, con el que soluciona el modelado formal de las partes y con el que pormenoriza transiciones cromáticas y volumétricas. Este rayado aparece en pliegues, drapeados y, sobre todo, en carnaciones, retrotrayendo trazos morfológicos propios de los lenguajes góticos más arcaicos. Igualmente, los estarcidos y salpicaduras, por ejemplo, sobre la piel del diablo, son un recurso técnico que ya comparece en obras como el Retablo de San Martín, Santa Úrsula y San Antonio Abad, de Gonçal Peris Sarrià, (Museo de Bellas Artes de Valencia), datado hacia I440.

Así, las hechuras pictóricas de Joan de Rua, aprendidas de la mano de Reixac, revelan una gran capacidad de trabajo con el temple, al que - pese a sus consabidas limitaciones-, pone al servicio de facturas que llegan a devenir nota- 
blemente efectistas, como acontece con el resto de los maestros que pivotan, técnicamente, entre la témpera y el óleo. En general, y también como sucede con todos los pintores considerados hispano-flamencos, adolece una cierta falta de atención a la luz en pos de un uso todavía muy medieval del color, relativamente plano. No obstante, aunque sea de manera superficial, reflejos, destellos, texturas y otros efectos propios del naturalismo son asimilados progresivamente, como demuestran sus pinturas. Pero admitamos también que, en esencia, el conjunto de características técnicas y procedimentales de estos maestros supone un paso hacia adelante en la superación definitiva del Gótico Internacional, aun cuando encontremos lógicos débitos a la tradición precedente.

Volviendo al caso del Retablo de San Miguel, por ejemplo, el temple graso utilizado genera en algunos puntos una película traslúcida que crea un cierto efecto de color plano y poco cubriente. La ejecución pictórica se realiza a partir de esta base de tinta plana, a la que se superponen finas pinceladas que no llegan a fundirse en muchas ocasiones (probablemente ejecutadas también con témpera), formando el característico tratteggio, en el que cada trazo describe la direccionalidad de los volúmenes. Las carnaciones en muchas de sus figuras - acaso por la presencia de yema - resultan mucho más opacas que otras zonas, como ciertos mantos, en los que, por su transparencia y su aspecto lustroso no puede excluirse el uso del óleo. Sin embargo, la incipiente técnica de las veladuras parece ceñirse al uso de lacas y barnices coloreados, aplicados, de nuevo, en tintas planas y no mediante el típico rallado propio de la témpera, otorgando una especie de baño cromático que tinta y envuelve las construcciones subyacentes. Los verdes parecen veladuras oleorresinosas de cardenillo, con su característico color y, sobre ciertos tonos rojos de bermellón aplica superficialmente intensos estratos de rojo carmín y lacas de diversa naturaleza que, puntualmente, también utiliza a tratteggio. En el caso del forro interior de la capa del arcángel, en cambio, la aplicación de la laca está realizada con descargas horizontales, simulando un jaspeado de terciopelo, recurso análogo, al utilizado por Jacormart y Reixac en otras tantas obras, como el San Sebastián de la Seu de Xàtiva, por ejemplo.

Así, como puede deducirse durante el periplo valenciano, Joan de Rua asimila, no solo las enseñanzas técnicas de Reixac, sino ciertos preceptos plásticos y estilísticos de la tradición local, integrando las novedades del incipiente flamenquismo que abanderan figuras como Lluis Dalmau, el desconocido «Maestro de Bonastre» (si es que no son la misma persona), o Lluis Alincbrot, caracterizados por un mayor dominio del óleo, en comparación con otras figuras como Jacomart.

En lo que al dorado se refiere, de Rua combina, como se ha anticipado, soluciones típicamente valencianas con otras más habituales de los territorios del 
norte de la Corona de Aragón: un uso de repicados y cincelados juntamente con resaltes en pastillaje (embotits) es un rasgo típico de su producción, que pudo incluso tener cierto impacto en años sucesivos; como muy característica es también la abundancia de tejidos damasquinados. Se trata, seguramente, de un estilemas que acusan el doble débito formativo al que anteriormente hemos aludido, con aspectos característicos de las facturas aragonesas y otros típicamente valencianos.

Antes de concluir nos parece pertinente una reflexión sobre el reciclaje de motivos tomados de obras de Joan Reixac. Durante el siglo xv, los talleres pictóricos europeos desarrollaron mecanismos para convertirse en centros más expeditivos ante una demanda creciente de modelos afortunados. Este fenómeno se da en paralelo en los territorios flamencos, italianos, hispanos, o franceses. La reutilización de determinadas composiciones, o fragmentos de las mismas - figuras, motivos, patrones, arquitecturas etc.- se convirtió en un hecho común en la mayoría de los obradores, donde, además, por lo general, solían conservarse los bocetos, trazas, muestras, plantillas, trepas y dibujos de las composiciones más afortunadas, y tanto el maestro como los discípulos y aprendices podían utilizarlos siempre que se precisaba (Herrero-Cortell, 20I8, pp. 92-93). El haber pasado por el taller - y probablemente colaborado en muchas de las obras que posteriormente imita - legitimaba a Joan de Rua a hacer uso del repertorio que conocía; el mismo con el que se había formado pictóricamente. Esto constituía una práctica muy habitual en los siglos xv y xvI, que era seguida especialmente por colaboradores, discípulos y epígonos. ${ }^{18}$ La copia de dibujos y pinturas y su sucesivo reciclaje, se erigieron pronto como sistemas eficaces de trabajo y, frente a una elevada demanda, se encuentra así una manera de aumentar la oferta y reducir el tiempo de trabajo (Herrero-Cortell, 20I8, pp. 92-93).

\section{CONCLUSIONES}

Con el documento que hemos dado a conocer en este trabajo, consideramos zanjado el debate sobre la formación pictórica de Joan de Rua. Si hace unos

${ }^{18}$ Algunas reflexiones a propósito de las copias el ambiente valenciano de los siglos XV y XVI en Herrero-Cortell, 20I8, pp. 8I-I06. La apropiación de motivos aparece ya explicada desde Cennini, quien, por ejemplo, comenta la fabricación de papeles transparentes o carte lucide indicando que resulta "muy útil para calcar una cabeza o una figura según se encuentre de la mano de grandes maestros» (Cennini, 1998, p. 52). 
años (2015) se identificaba al anónimo «Maestro de Cervera» con Rua, ahora conocemos la parte más importante de su formación, sus años junto al pintor Joan Reixac, operando directamente en su taller, momento en el que recopiló todo tipo de fórmulas compositivas y cimentó un estilo que después, en solitario, utilizaría en sus obras.

Tras su periplo valenciano, Joan de Rua debió de actuar como una suerte de propagador de las formas meridionales en territorio catalán, exportando con sí tanto claves estilísticas —imágenes y lenguajes - como metodológicas, al abanderar las novedades de esa incipiente experimentación con la técnica al óleo, en la que ciertamente Valencia ostentaba una posición diferencial y en la vanguardia, embrionaria en la Corona de Aragón.

Todavía hay algunos temas que plantean numerosas incógnitas por descubrir: desconocemos, por ejemplo, su aprendizaje inicial, que posiblemente debió ser con algún pintor aragonés, por ser natural de Zaragoza. Tampoco sabemos exactamente el tiempo que estuvo trabajando con Reixac pues, aunque su contrato era por tres años, hemos expresado nuestras sospechas de que debieron ser algunos más, estableciendo su taller definitivo en Montblanc hacia finales de la década de los años sesenta del cuatrocientos.

Escapa de nuestra pretensión y tampoco es nuestro objetivo en este trabajo, presentar el nuevo catálogo de las posibles obras atribuibles al ahora conocido Joan de Rua - y menos sin razonarlo_- ya que la mayoría de las piezas no las hemos podido ver directamente. No estamos, por ello, en condiciones de valorar —ni para engrosar ni para cuestionar - aquellos intentos de catalogación realizados sobre fotografías, a menudo de escasa calidad. Es cada vez más necesario servirse de estudios técnicos que permitan ahondar en el conocimiento de esas pinturas, de su proceso creativo, y no fiarlo todo a los ojos omniscientes que a menudo se muestran falibles.

En todo caso nos limitamos, a continuación y para concluir, a enumerar todas aquellas obras que actualmente se atribuyen a Joan de Rua, ${ }^{\text {I9 }}$ conscientes de que algunas, seguramente, habrán cambiado de propietario. Valga al menos esta lista como un somero esbozo; una pauta que sirva de punto de partida para ulteriores

19 En todo caso destacar algunos intentos de catalogación del maestro, como en la magna obra de Post, vol. VII, I938, pp. 575-594 (así como en apéndices de los vols. VIII, p. 746; X, p. 384; y XII, p. 350); Gudiol-Alcolea, 1987, pp. 203-204 y Velasco, 20I0, pp. 84-IOO. 
investigaciones con el propósito de esclarecer aspectos de tan esquiva personalidad artística: ${ }^{20}$

Museu Episcopal de Vic

Retablo de San Miguel, de Verdú (inv. I768-I77I) (Fig. I. B)

Lapidación de santa Emerenciana (inv. I0745) (Fig. 8. E)

Cristo Varón de Dolores, San Juan Evangelista y Santo Obispo, tres compar-

timentos de predela (inv. I0745) (Fig. 8. H)

Calvario (Fig. 8. A)

Epifanía (Fig. 3. C)

San Remigio bautizando al rey Clodoveo (Fig. 8. F)

Museu Comarcal de Cervera

Retablo del Ángel Custodio, de Santa María de Cervera, tres tablas con: San

Miguel (central), Anunciación y Adoración de los pastores (calle lateral)

(Fig. I. A), y San Bartolomé, Virgen Dolorosa, Cristo Varón de Dolores,

San Juan Evangelista y María Magdalena (predela).

Virgen Dolorosa, fragmento de predela (Fig. 8. G)

Iglesia de Vilanova de Bellpuig (Urgell)

Retablo de la Virgen del Lirio, en la iglesia de Vilanova de Bellpuig (Fig. 2. B)

Museu Diocesà i Comarcal de Solsona

Retablo de San Pedro (siete tablas): San Pedro en cátedra (central), Vocación de San Pedro, Jesús entrega las llaves del cielo a Pedro, Quo vadis?, Crucifixión de San Pedro (escenas laterales) y dos fragmentos de predela con: San Sebastián, Santa Lucia y San juan Bautista, y San Miguel y Santa María Magdalena, (Fig. 2. A: inv. 3I, 34 y 35).

Museu Diocesà de Tarragona

Retablo de San Eloy y santos Abdón y Senén de la iglesia de San Miguel de Montblanch, dos tablas con: San Eloy (Fig. 9. A) y San Abdón y Senén (Fig. 9. B: inv. 43 y 44).

${ }^{20}$ El orden utilizado a la hora de enumerar las obras de Joan de Rua, así como su ubicación conocida, no responde a un criterio cronológico. Hemos creído más apropiado, para esta ocasión, empezar por las que inicialmente formaron parte del corpus pictórico de la personalidad artística en cuestión, y continuar con aquellas que progresivamente se han propuesto incluir en su producción. 
Museu Nacional d'Art de Catalunya (MNAC, Barcelona)

San Pedro y S. Juan Bautista, Cristo Varón de Dolores, Santa Eulalia y Santa Apolonia, Sant Bartolomé y Santa Margarita (Fig. 9. C: cuatro compartimentos de predela, inv. 1942, en depósito en el Museu de Lleida).

Fine Arts Museums of San Francisco, California (EE.UU.) ${ }^{2 \mathrm{I}}$

San Jorge y el dragón (Fig. 8. B)

Kleinberger \& Company, París

San Martín

Auckland Art Gallery (Nueva Zelanda)

Santa Ana, la Virgen y el Niño (inv. 1966/26) (Fig. 4. E)

Los Angeles County Museum of Art (Los Ángeles, EE.UU.)

Cristo entregando las llaves del cielo a san Pedro

Staatliches Museum de Schwerin (Alemania)

Pentecostés y Dormición de la Virgen

Colecciones particulares

Verona, Epifanía (Fig. 3. D)

París, San Antonio abad tentado por el diablo personalizado en una mujer

Madrid, San Abdón y Senén

Argentina: Flagelación y Camino del Calvario. ${ }^{22}$

Barcelona, San Miguel Arcángel (predela)

Barcelona, Santo Obispo

Obras en comercio

San Miguel, Christie's (Londres, King Street), 8 de julio de 2005 (Fig. 6. D)

San Damian (?), Setdart, marzo 2008 (Fig. 8. I)

San Pedro, en comercio en París en 1960.

${ }^{21}$ Medidas: 132,4 × $94 \mathrm{~cm}$. Inv. 1956.I6. Adquirida el I3 de abril de 1959 a The Sidney M. and Florence H. Ehrman Fund.

${ }^{22}$ Medidas: $90 \times 68,5$ y $94 \times 70 \mathrm{~cm}$ respectivamente: Corti, 1995, pp. 29I-298. 


\section{ANEXO DOCUMENTAL}

I463, julio, I8 - Valencia

Contrato de aprendizaje-perfeccionamiento entre Joan de Rua y el pintor Joan Reixac.

Archivo Protocolos del Colegio de Corpus Christi, Valencia, Protocolo de Joan Erau, núm. 24.704:

Localizado: Proyecto financiado por el Centro de Arte de Época Moderna (CAEM) de la Universitat de Lleida (coordinado por el CIMM de la UPV).

Die lune decima octava iulii, anno a Nativitate Domini MoCCCCo sexagesimo tercio. Iohannes de Rua, maior de XXti annorum, oriundus civitatis Ceçarauguste regni Aragonum, gratis et cetera cum hoc publico instrumento mitto et affirmo me vobiscum, honorabile Iohanne Rexach, pictore, cive Valencie, presente et acceptante, in discipulum et servicialem vestrum in arte vestra faciendum omnia vestra mandata et cetera, ad tempus trium annorum, qui currere inceperint primo die mensis madii proxime lapsi, et hoc pro solidata quindici florenorum monete Valencie currencium, ad racionem undecim solidorum pro floreno uno, solvendorum per vos mihi annis singulis. In quolibet dictorum trium annorum in terminis mihi visis ad opus mei induendi et calciati et aliorum necesitatum, et infra dictos tres annos huiusmodi afirmamenti teneamini me tenere in domo et servicio vestri provisum de cibo et potu tammodo et tam sanum quod egerit, emendando cum vobis tempus infirmitatis duos dies pro uno. Promittens et iurans et cetera, quod ero vobis et domui vestre bonus et legalis et cetera, et quod non fugiam neque a domo vel servicio vestri non disidam, quod, si fecero, dono vobis licenciam et plenum posse quod possitis me capere et capi facere et cetera, et tenear emendare tempus fuge et absencie unum diem pro alio, et sich obligo vobis personam nostram et bona mea. Ad hec autem ego, dictus Iohannes de Rexach, gratis et cetera, acceptans et cetera, promitto et cetera, obligo et cetera. Actum Valencie. Testes, Iohannes Perez, pictor, et Anthonis Sanxiz, cursor, cives Valencie 
I483, septiembre, I5 - Verdú

Contrato para la ejecución del retablo de la ermita de San Miguel Arcángel de Verdú, firmado entre los jurados de la vila y rector de dicha ermita con el pintor Joan de Rua.

Archivo Parroquial de Verdú. Bernardin de Sant Joan, presbítero, vicario y notario, Manual notarial, I482, sept., I9 - I483, nov., 25 [sign. 53/I]

Pont, 2015 (sin transcripción)

La transcripción completa e inédita la aportamos a continuación (agradecemos a Lluïsa Tolosa, de la Universidad Politécnica de Valencia, la transcripción del mismo)

I5 de setembre de 1483

En nom de Déu sie e de la Verge madona Santa Maria e de tots los sants e santes del paradis, amen.

Capítols fets per los honorables senyors de jurats de la vila de Verdu, en Santjacme, Pere Rialp, Guillem Claver e Jacme Mora, e mossen lo batlle e en presencia de mi, Bernat Sentjohan, prevere, [arendador] de la sglessia de Verdú e los [capitat] de la capela de Sant Miquel, ab consentiment e de libertad de tot lo consell de dita vila de part una, e mestre Johan de Rua, pintor habitant de la vila de Monblanch de part altra, sobre los pactes e concòrdia del retaule de la sglessia de Sent Miquel fora los murs de la dita vila en la forma següent:

E primerament, que lo dit mestre Johan aje e sie tengut de fer un retaula de fusta de amplaria de VIII palms de alna de Monblanc e dotze palms de alt sot invocació de l'arquangell sent Miquel, so és ab altres devocions seguons será scrit en la mostra sobre la qual avem feta dita concòrdia, e dita mostra reste en poder de dit mestre Johan pintor, scrit en cada part de dita mostra e de mà de mossen Bernat Sentjohan, prevere en les cosses que per dit mestre Johan Rua a ésser pintades en dita retaula, a les quals dit mestre Joahn sa obligua.

Es pactat que dit mestre Johan en preu de [dar] recapta en dit retaule de bona ffusta e axi matex totes les tubes pilars e campes e maçoneria, tot daurat de or fi e images principals [que est dit de] brocat de or e d'atzur, seguons se requira, tot de or fi, que dit mestre Joha promés de no obrar res de or partit e tot assó promet 
tenir, servar e cumplir dit mestre Johan sots obligacio de tots sos bens, ajuts e avedors e a tot son etc.

E més, promet dit mestre Johan donar ab tot acabament, dit retaule de si per tot lo mes de febrero primer vinent cum obligació, etc.

E més, es estat pactat e concordat entre les dites parts que dit mestre Johan a de aver per preu de dit retaule e tots altres cosses per ell fahedores coranta lliures barchinonensis en la forma seguent, so es, ara de present una tertia de dites coranta lliures, l'altra terç com se sie enfustat, enguixat e més de sissa per a daurar, e l'altra terça per acompliment de dites coranta lliures quant sera acabat e possat en la sglessia de Sent Miquel. Les quals coranta lliures los honorables Johan Sentjacme, Pere Rialp, Guillem Claver e Jacme Mora, jurats l'any present de la dita vila en nom de la universsitat avent plen poder seguons conste per conssell sobre aquestes cosses tengut, prometen de de donar al dit mestre Johan de cumplir e paguar dites coranta lliures en la forma dessús dita, son obliguats de tota la universitat.

Ítem més, es concordat entre les dites parts que lo dit mestre Johan doni bona e sufficient fermança, fahent star ab segur dita universsitat de tot sò e quant per dit Mestre Johan será rebut en cars que per ell no fos atés ni complit les cosses en dits capitols contengudes. Axí ho promet.

Ítem més, es pactat e concordat entre les dites que quant lo dit retaula aura compliment, dit retaule aje ésser portat a càrrech de la universsitat, entés enperò si en lo port ni en lo possar se [...] alguna cosa, dit mestre Johan aje adobar [...] essent obliguada enperò la dita universsitat en dar fusta per ajudar a dit mestre Johan en possar dit retaula, e aquel aje a paguar dita universitat en no dit mestre Johan.

E més, es concordat entre les dits parts que dels presents capitols se pusque fer carta e cartes, una e tantes.

Testes [vocats] e roguats sunt discreti Iohannes Raimundi e [Inocencius] Soribes, presbiteri ville de Verdu, habitantes.

BIBLIOGRAFÍA

Alanyà, J., 2015: «El pintor Miquel Nadal a Tortosa. El retaule de la capella del Mas del Bisbe (Bítem)», Boletín de la Sociedad Castellonense de Cultura, núm. 9I, pp. 345-360.

Alcoy, R., 1990: «Retaule i Predel.la», en Museu Diocesà i Comarcal de Solsona. Romànic i Gòtic, pp. I89-I9I. 
__ 200I: «Retaule de l'Àngel Custodi (taula central i carrer lateral). Mestre de Cervera o Pere Girard», Cervera. Tresors secrets... La formació d'un museu, en Bergés, C. (coord.), Cervera, pp. 53-56.

Balasch, E., 1993: "Retaule de l'arcàngel Sant Miquel de Cervera (Segarra)», en I Congrés d'Història de l'Esglèsia Catalana. Des dels orígens fins ara, vol. II, Solsona, pp. 547-555.

_- I995: "Noves dades i aportacions a l'estudi del retaule de sant Miquel i l'àngel Custodi de Cervera», Urtx. Revista Cultural d'Urgell, n. 7, pp. 39-48. Beserán, P. y Alcoy, R., 1994: «Notícia sobre la procedència pobletana del retaule de Santa Úrsula de Joan Reixac», Butlletí del MNAC, núm. 2, pp. I45-I5o.

Camps, Joaquim, 20ı0: «Sobre las medidas del retablo mayor de Santa María de Poblet», Unicum, 20Io, núm. 9, pp. 68-80 [en línea: <https://www.raco.cat/ index.php/UNICUM/article/view/287943>] [Consulta: 22-04-202I],

Cennini, Cennino, 1998: El libro del Arte, Akal, Madrid.

Cerveró, L., 1963: «Pintores valentinos. Su cronología y ducumentación», Anales del Centro de Cultura Valenciana, año XXIV, núm. 48, pp. 63-156.

- - 1966: «Pintores valentinos. Su cronología y documentación», Archivo de Arte Valenciano, pp. 19-30.

—_, 1972: «Pintores valentinos. Su cronología y documentación. Apéndice», Archivo de Arte Valenciano, pp. 44-57.

Company, X., I992: «Petjades valencianes en la pintura hispanoflamenca a Lleida. Notes sobre el Mestre de Javierre, Joan Reixac i Pere Girard», Miscel-lània Homenatge a Josep Lladonosa, Lleida, 1992, pp. 427-438.

- 2006a: «Pere Girard o el Mestre de Cervera», en L'Art gòtic a Catalunya, Pintura III: Darreres manifestacions, Barcelona, Enciclopèdia Catalana, pp. 220-22I.

—_ 2006b: Paolo da San Leocadio i els inicis de la pintura del Renaixement a Espanya, Gandía, Ceic Alfons el Vell

Company, X., Aliaga, J., Tolosa, Ll., Puig, I., Ramón, N., Rusconi, S., Argelich, M. A., 20I8: «Valencian Late-Gothic Painting Documents. Contributions of the Centre d'Investigació Medieval i Moderna (CIMM, Polytechnic University of Valencia and University of Lleida)", Late Gothic Painting in the Crown of Aragon and the Hispanic Kingdoms, Leiden - Boston, Brill, pp. 467-496.

Corbalán, J., 2003: "Consideraciones sobre el pleito del retablo de la Capilla de San Pedro en la Seo de Valencia y nuevos datos sobre Joan Reixac», Archivo de Arte Valenciano, pp. 189-193.

Corti, F., 1995: «En torno al Maestro de Cervera», Boletin del Seminario de Estudios de Arte y Arqueología: BSAA, t. 6I, pp. 29I-298. 
Durán y Sanpere, A., 1933: «Mestre Jeroni Rua de Montblanc i un frare mercedari, pintors de retaules», Boletín Arqueológico, núm. 45, pp. 265-270.

Español, F., 1998-I999: «El sepulcro de Fernando de Antequera y los escultores Pere Oller, Pere Joan y Gil Morlanes, en Poblet», Locus Amoenus, núm. 4, pp. 8I-IO6.

Fernández Somoza, G., «Mundo laboral del pintor del siglo xv en Aragón, El. Aspectos fundamentales», Locus Amoenus, 3 (1997), pp. 39-49

— I350-I500", en Miquel, M., Pérez, O. y Bueso, M. (eds.): Ver y crear. Obradores y mercados pictóricos en la España gótica (I350-I500), Madrid: La Ergástula, 2016, pp. 19I-208

Ferre Puerto, J., 1997: «Joan Reixac, autor de dues obres del cercle JacomartReixac», en Actes del Primer Congrés d'Estudis de la Vall d'Albaida. València, Diputació de València i Institut d'Estudis de la Vall d'Albaida, pp. 3II-320.

__ 2003: "Presència de Jaume Huguet a València novetats sobre la formació artística del pintor", Ars Longa: cuadernos de arte, núm. I2, pp. 27-32.

Framis, M. y Tolosa, Ll., 1996: «Pintors medievals a la Cort Reial de València», en El poder real de la Corona de Aragón: (siglos XIV-XVI), vol. 5, pp. 423-436.

Gómez-Ferrer, M., 1994: "Un nuevo contrato de Jacomart el retablo de la iglesia parroquial de Museros», Archivo de Arte Valenciano, núm. 75, 1994, pp. 20-24.

- 20IO: «Nuevas noticias sobre retablos del pintor Joan Reixac (act. I437I486)", Archivo de Arte Valenciano, pp. 39-52.

__ 2018: «Reflexiones sobre el pintor Lluís Dalmau a propósito de un retablo para Molins de Rei (I45I)», Locus Amoenus, núm. I6, pp. 5-I8.

Gómez-Ferrer, M. y Corbalán, J., 2003: «El retablo de la parroquial de Museros, obra de Joan Reixach", Archivo de Arte Valenciano, pp. 19-24.

Gudiol, J. y Alcolea, S., 1987: Pintura Gòtica Catalana, Barcelona, Edicions Polígrafa S.A.

Herrero Cortell, M. À., 20I8: «Del sacar de otras pinturas. Consideración de las copias pictóricas a la luz de los tratados y otros textos del Renacimiento: reputación teórica versus repercusión práctica». Revista de humanidades, núm 35, pp. 8I-IO6

—, 2019: Materiales, soportes y procedimientos utilizados en los obradores pictóricos de la Corona de Aragón (siglos XV y XVI). Una aproximación a través del paradigma valenciano (Tesis doctoral), Univsersitat de Lleida.

Limentari Virdis, C., 200I: «Dipinti quatttrocenteschi catalani in una collezione veronese: aggiunte a Jaume Ferrer II e al suo atelier», Verona Illustrata, núm. I4, pp. 2I-3O. 
Miquel, M., 2008: Retablos, prestigio y dinero. Talleres y mercado de pintura en la Valencia del gótico internacional. Valencia, PUV.

Molina, J., 2006: "Al voltant de Jaume Huguet», en L'Art gòtic a Catalunya, Pintura III: Darreres manifestacions, Barcelona, Enciclopèdia Catalana, pp. I22-I46.

Montero, E., 2013: La transmisión del conocimiento en los oficios artísticos: Valencia, I370-I450, (Tesis doctoral inédita), Universitat de València.

Montolío, D. e Igual, D., 200o: Las Madres Agustinas en la Villa de Rubielos de Mora. 350 años de arte e historia, Rubielos de Mora.

Nicolau Bauzá, J., I985: «Pleito sobre un retablo del pintor Juan Reixac», Archivo de Arte Valenciano, València, pp. 34-35.

Pont, X., 20I5: "Identificació del "Mestre de Cervera” a l'arxiu parroquial de Verdú», Xercavins, núm. 62, juliol, pp. 19-2I.

Post, Ch. R., 1938: The Catalan School in the Late Middle Ages (A History of Spanish Painting, vol. VII, part II), Cambridge, Mss., Harvard University Press.

Puig, I., 2004: Documents per a la història de l'art de l'esglèsia parroquial de Santa Maria de Verdú, Tàrrega, Col-lecció Ardèvol.

—, 2005: Jaume Ferrer II. Pintor de la Paeria de Lleida, Lleida, Pagès Editors.

Sanchis Sivera, J., I909: La catedral de Valencia. Guia histórica y artística, Valencia, Imprenta de Fco. Vives Mora.

- , I912: «Pintores medievales en Valencia», Estudis Universitaris Catalans, tomo VI, octubre-diciembre, pp. 444-47I.

- - I913: "Pintores medievales en Valencia», Estudis Universitaris Catalans, tomo VII, enero-junio, Barcelona, pp. 25-II3.

_- 1929: "Pintores medievales en Valencia», Archivo de Arte Valenciano, Año XV, Valencia, pp. 3-64.

- 1930: Pintores medievales en Valencia, Valencia, Tipografía Moderna.

Sanpere y Miquel, S., 1906: Los Cuatrocentistas catalanes. Historia de la pintura en Cataluña en el siglo XV, vol. II, Barcelona, tipografia L'Avenç.

Segura y Valls, J., I895: «Más sobre el retablo de San Miquel del Museo Episcopal», La Voz de Montserrat, XVII, núm. 20, pp. I54-I55.

Sureda, M., 2017: "Com creix una col-lecció episcopal: els primers deu anys de vida del Museu Episcopal de Vic (I889-1900)», en Velasco, A. y Sureda, M. (coords.): La formació de col.leccions diocesanes a Catalunya, Lleida, pp. 89II4.

Tormo, E., I9I3: Jacomart y el arte hispano-flamenco cuatrocentista, Madrid, Centro de Estudios Históricos.

Velasco, A., 2002: «El retaule de la Mare de Déu del Lliri de Vilanova de Bellpuig», Quaderns de "El Pregoner d'Urgell», n. I5, 2002, pp. 63-88. 
Velasco, A., 20IO: «De pintura tardogòtica catalana algunes novetats al voltant del Mestre de Cervera i el Mestre de Gualba», Miscel.lania Cerverina, n. 20, pp. 83-I27.

—_, 20IO: «Les restes d'un retaule del Mestre de Cervera conservades al Museu Episcopal de Vic (MEV I0745) i una taula adquirida pel Museu Comarcal de Cervera», Quaderns del MEV, IV, pp. I33-I40.

Verdés, P., 2003: «L'obreria de l'església de Santa Maria de Cervera», Miscel.lània Cerverina, núm. I6, pp. 165-193. 


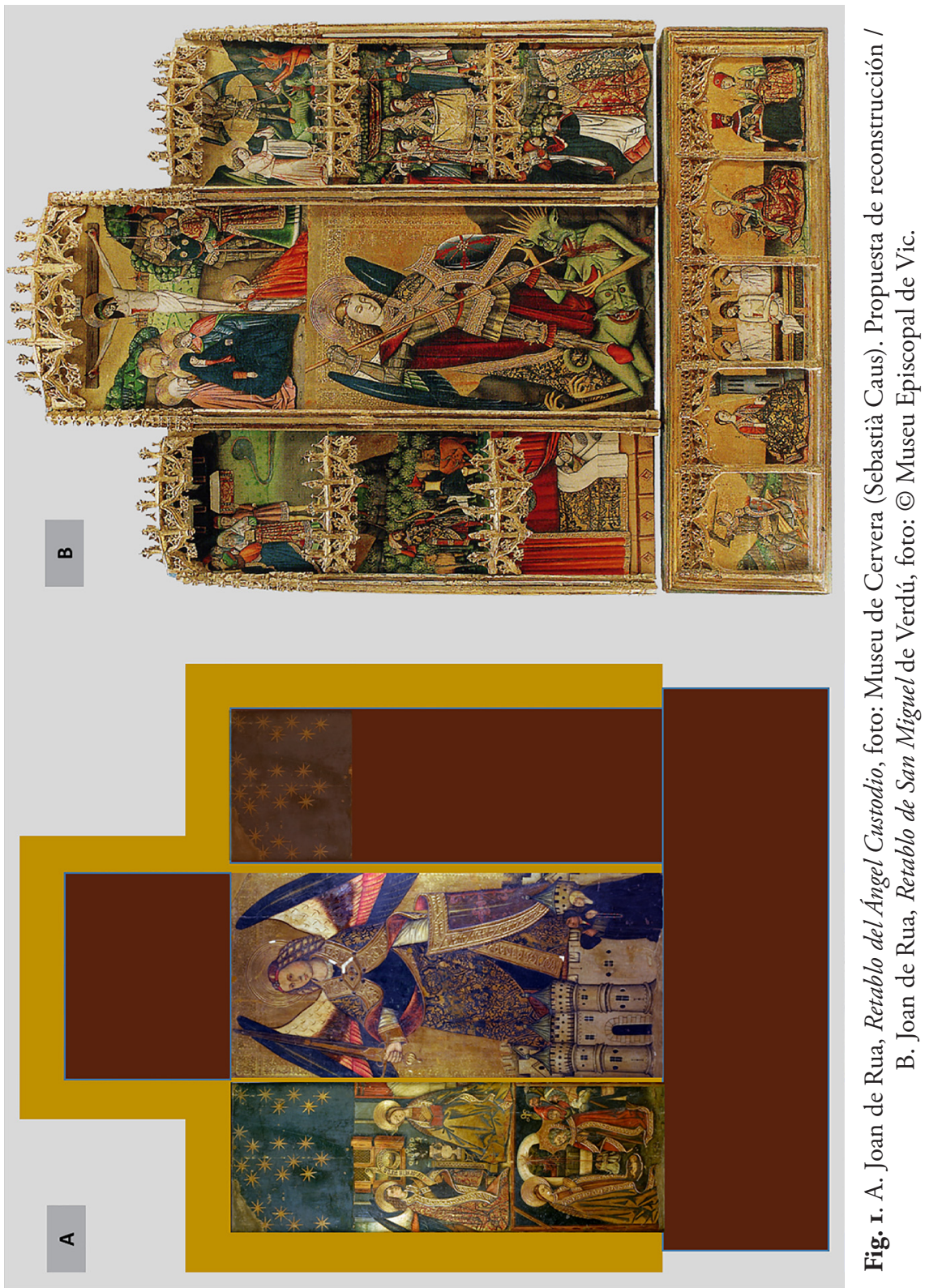




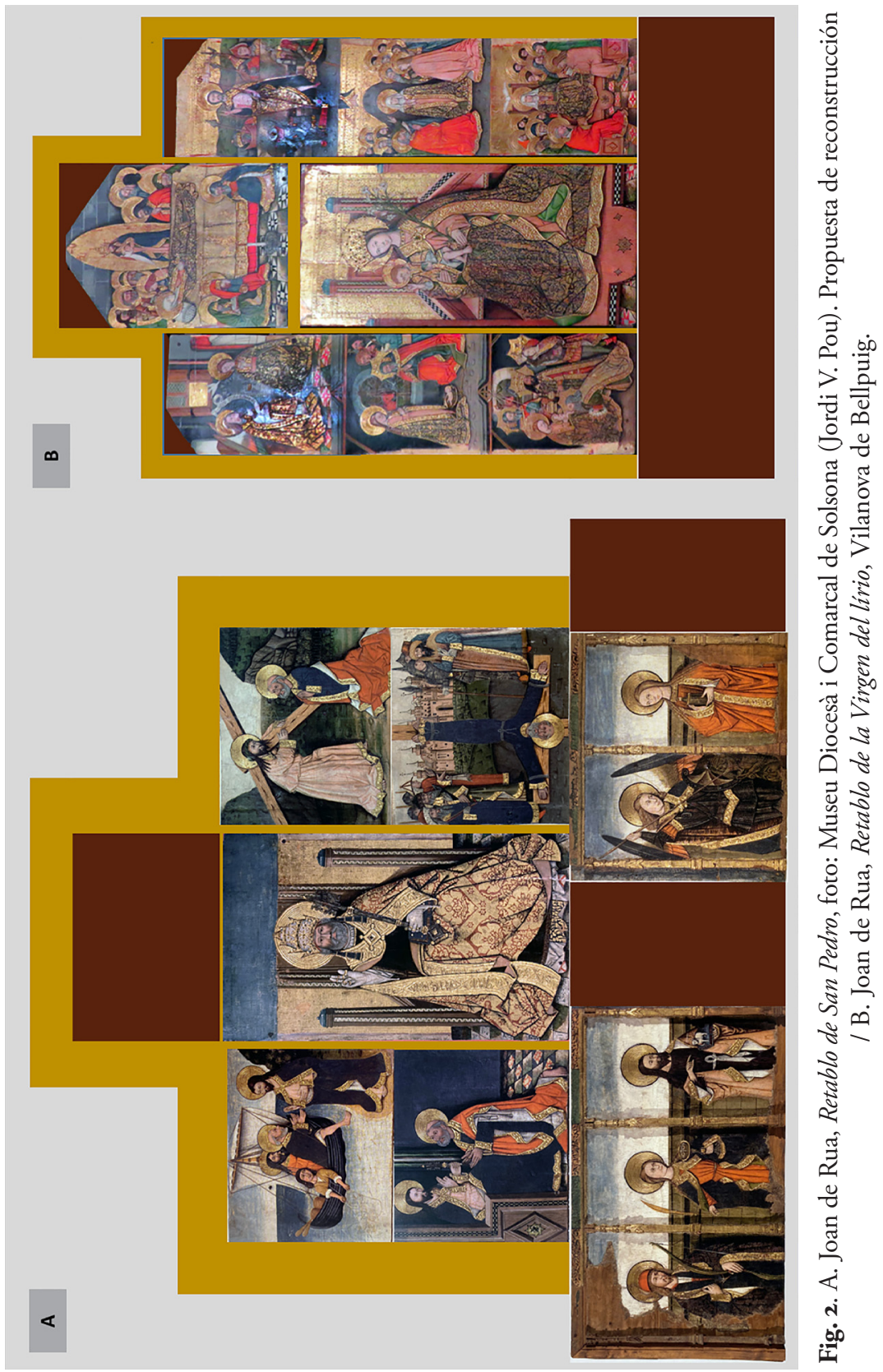



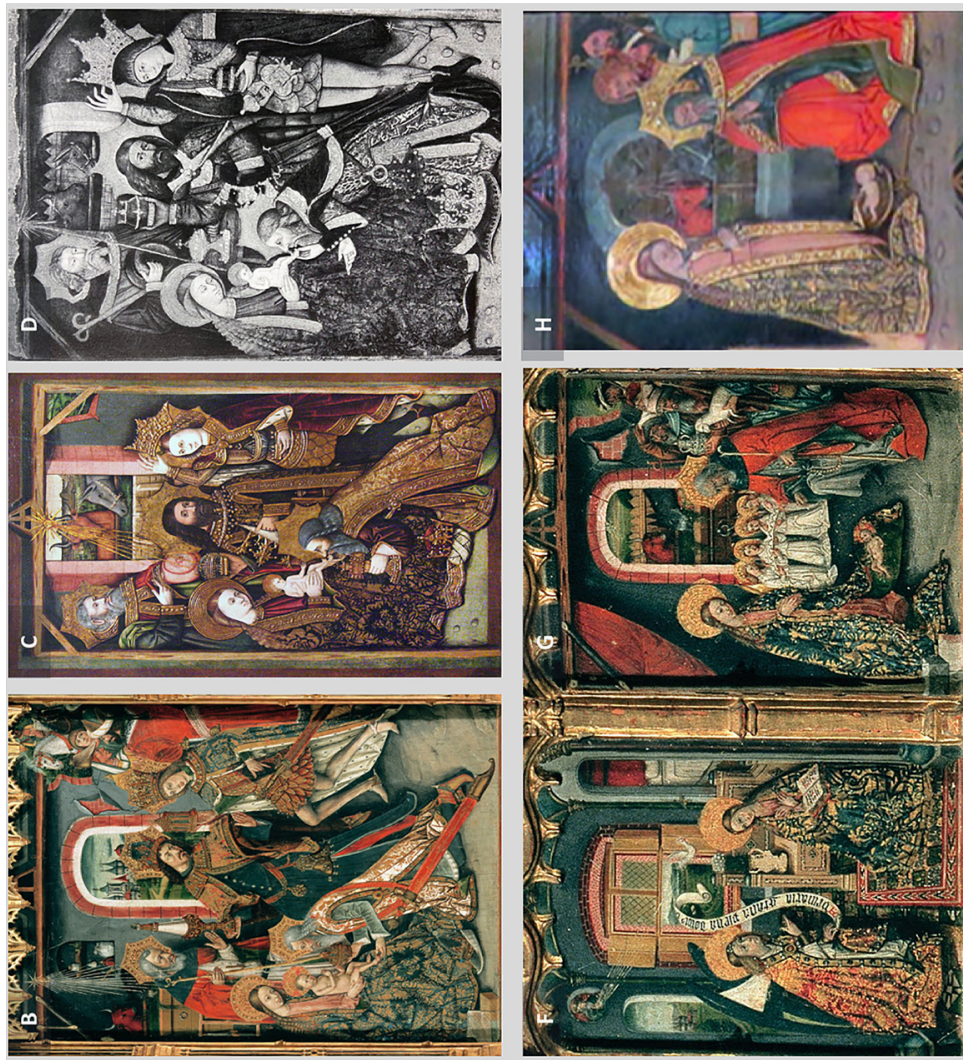

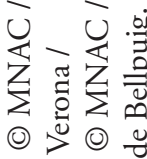

若

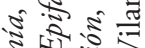

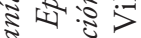

ล.

14

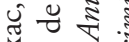

ब

$\underline{1} ㅇ$

ปี่

صं

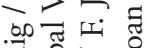

光 우요.

를

되흐

च च

릴 $\frac{0}{2}$

구 (2) व (2)

$>\ddot{0}$ 范

20 050

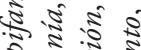

武告

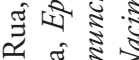

य 난

สี ช

$\stackrel{\circ}{*}$ 워

$\varangle \stackrel{\circ}{=}$

ค่ $\dot{0}$ 응
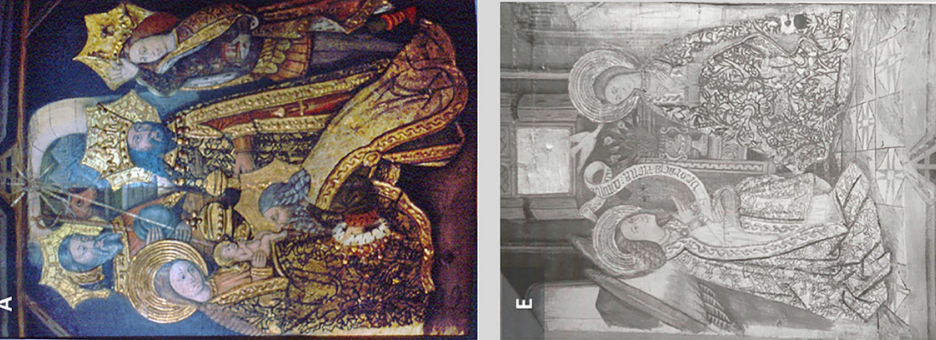

ம் 

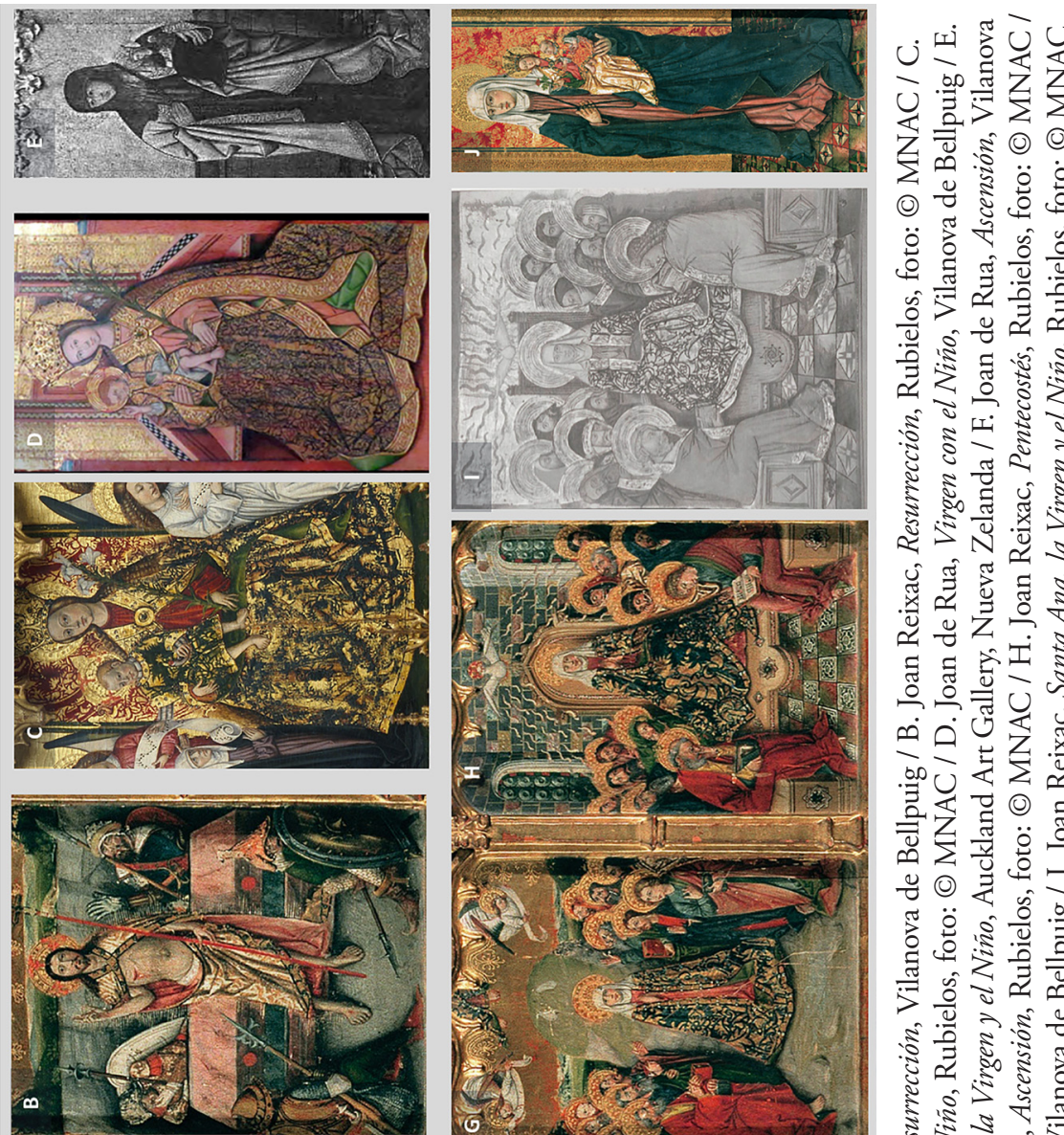

(2) चु

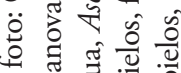

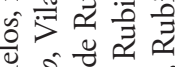

$\therefore$ श च

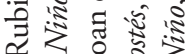

$\therefore \stackrel{2}{2} \underset{2}{2}$

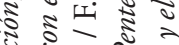

ปัँ

ริ
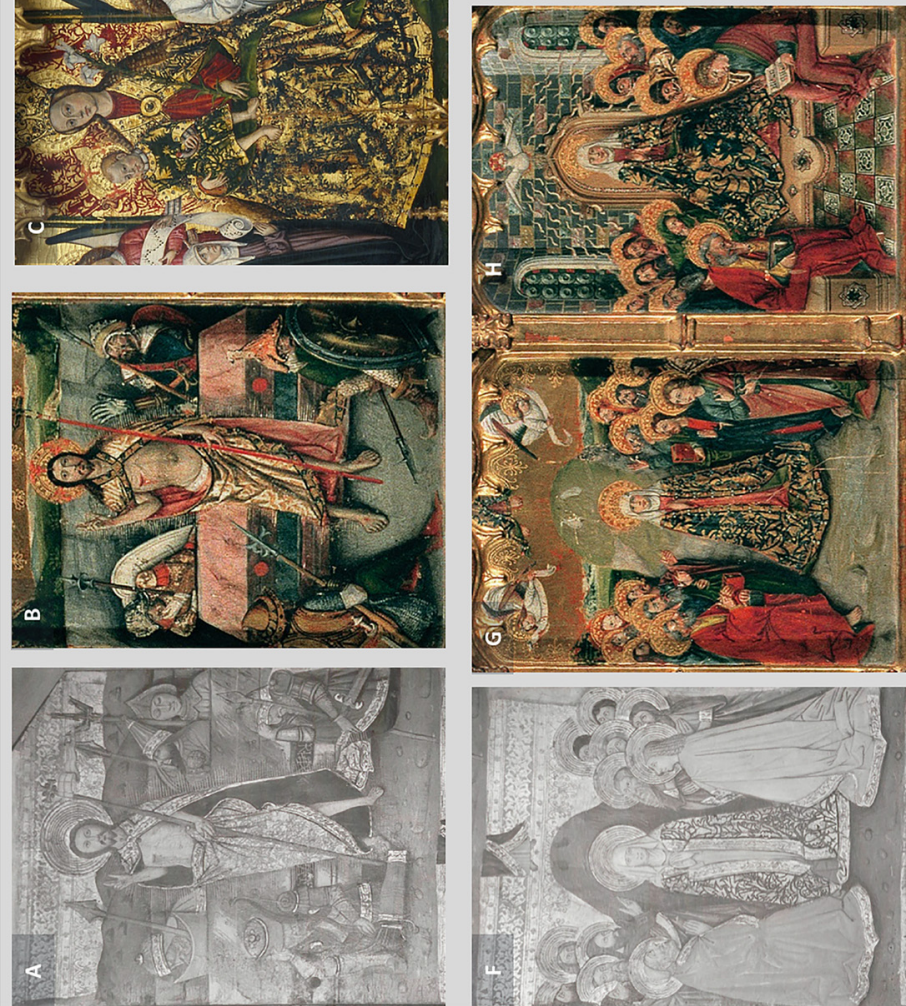

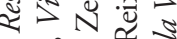

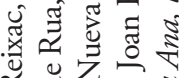

× $\frac{0}{2}$

สี สี

คํํㄴ

츤

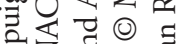

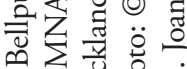

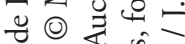

\%

的芝表

>

ร.ำ

2.

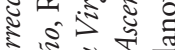

露

कर

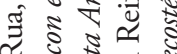

เ

ช

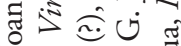

웅

< 藏

$\dot{4} \simeq$

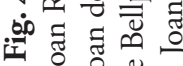



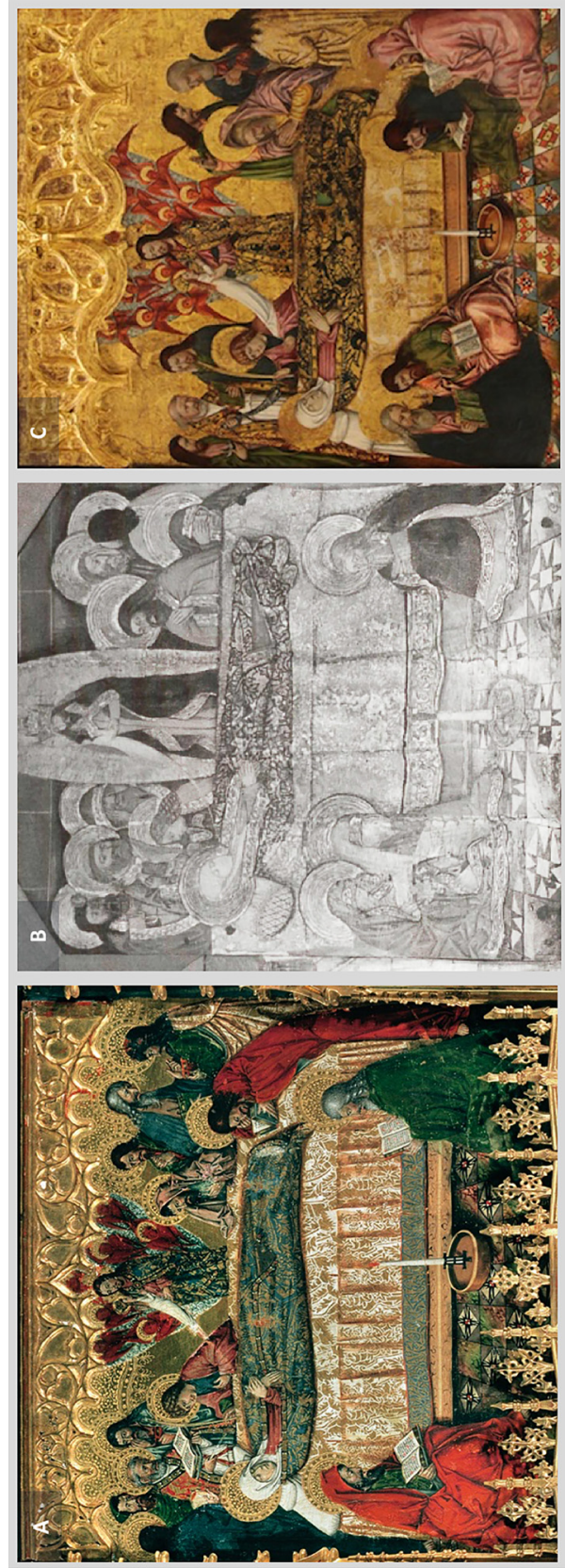

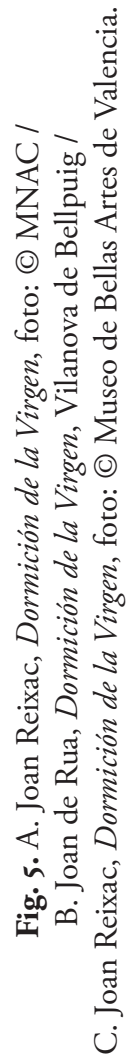




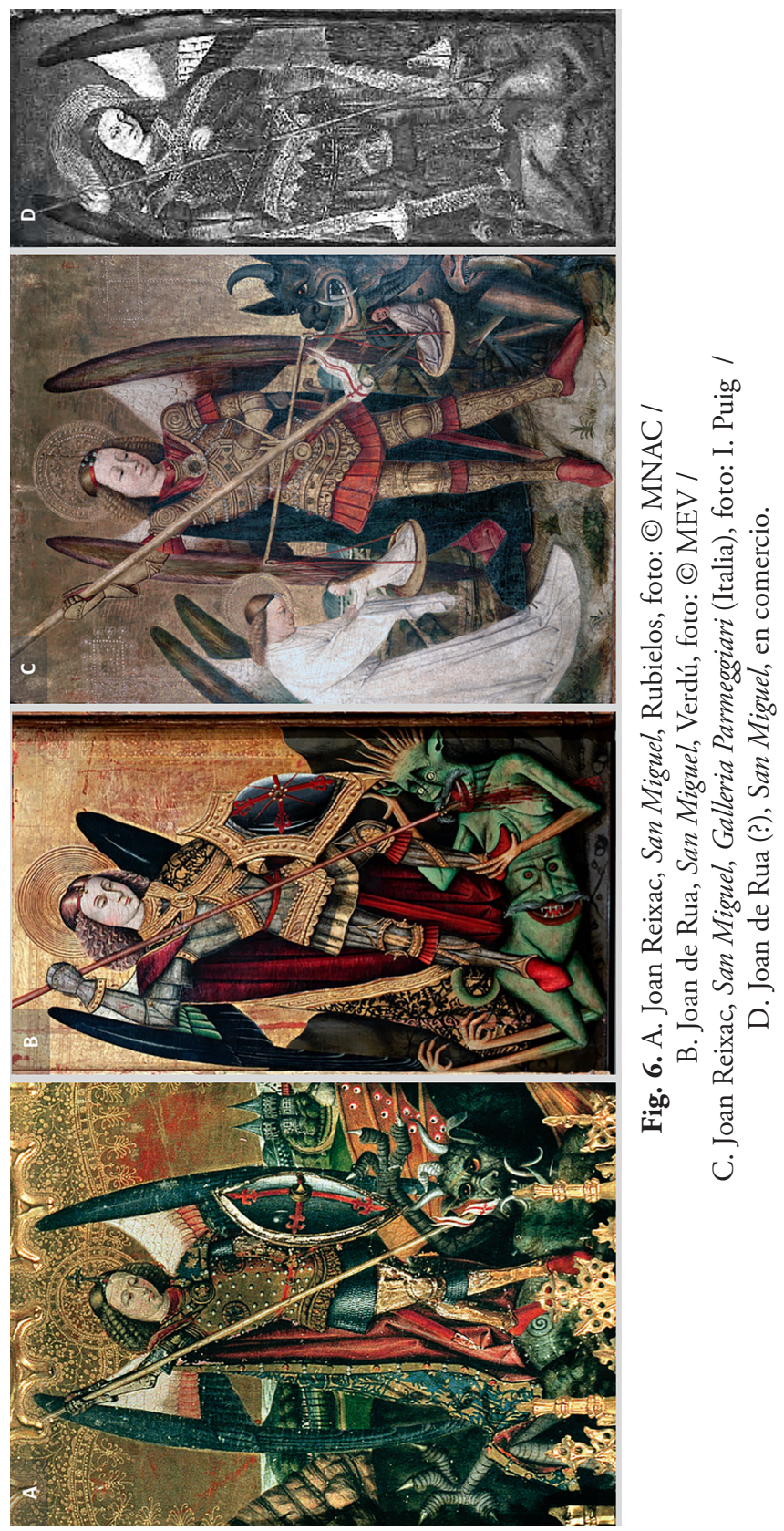



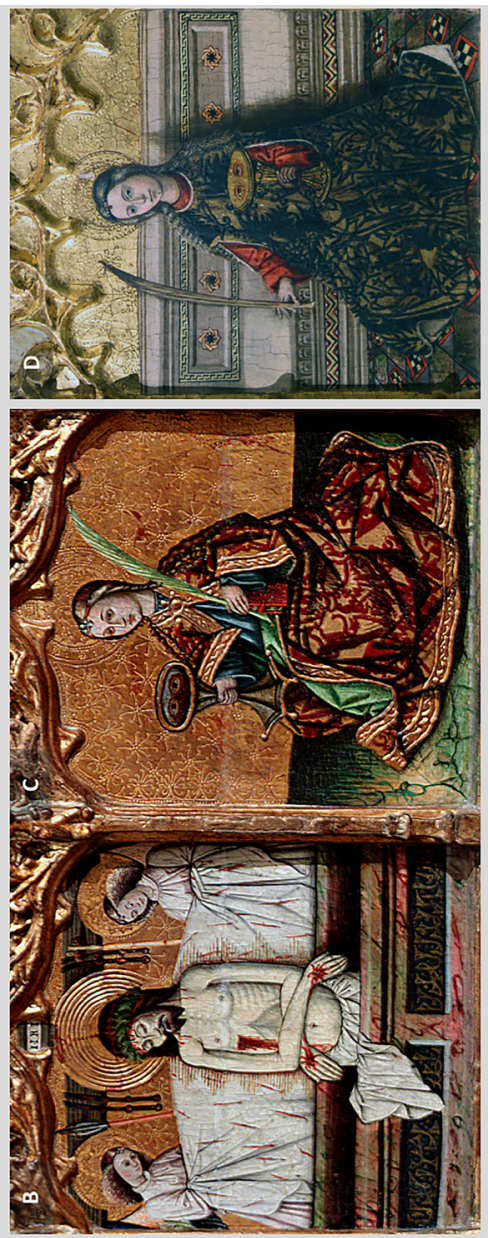

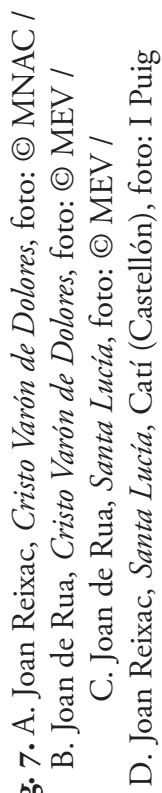

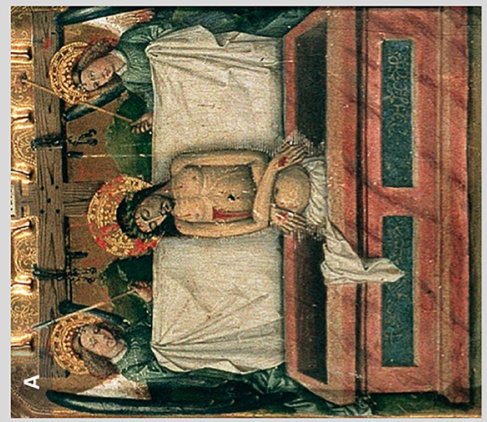

이 

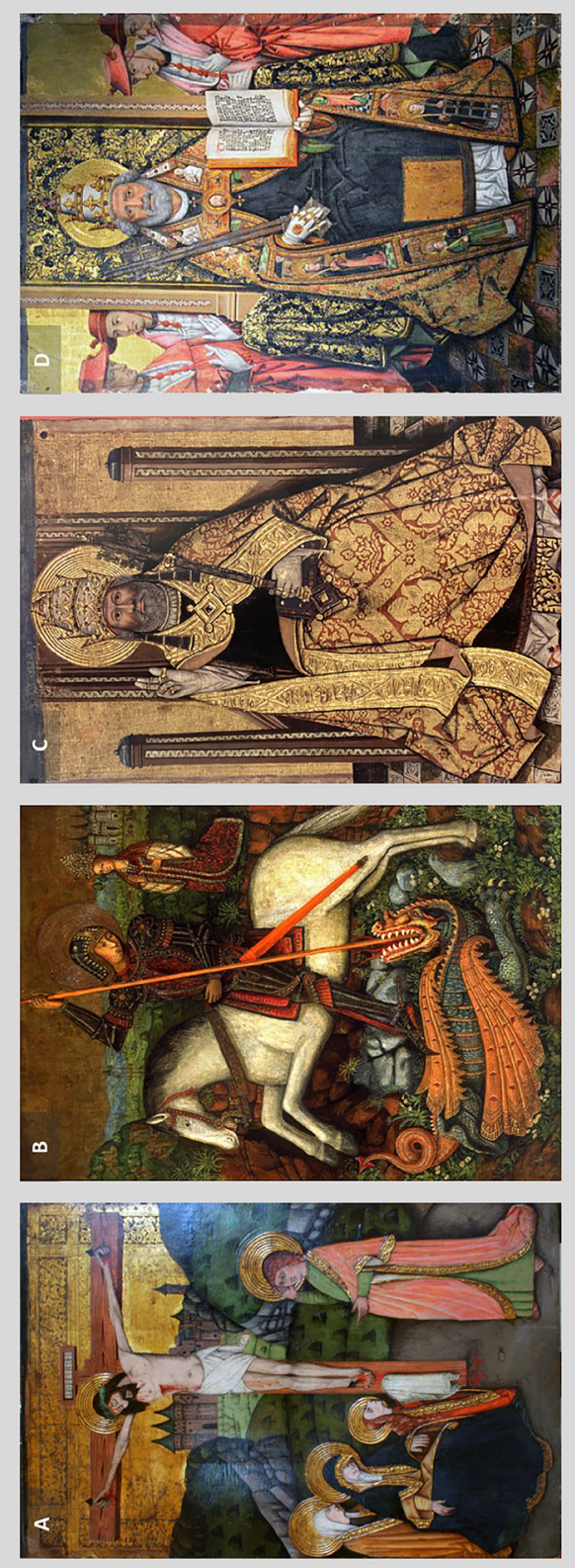
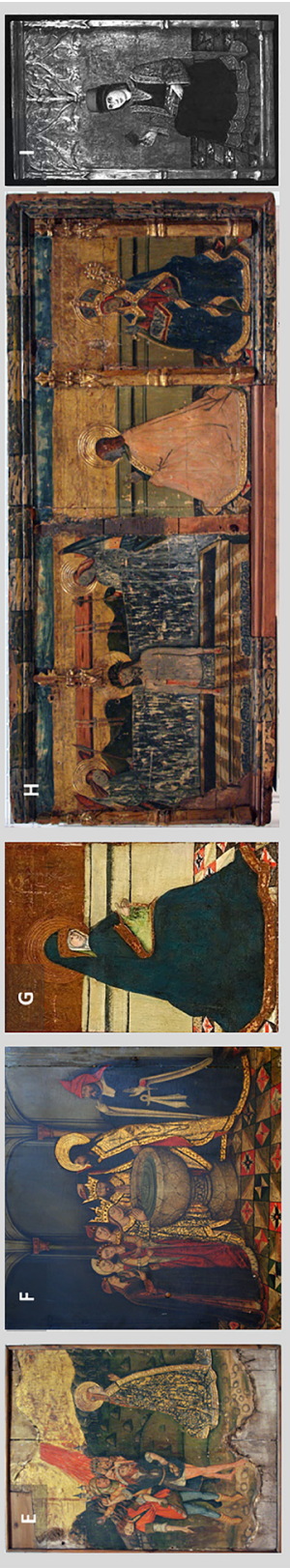

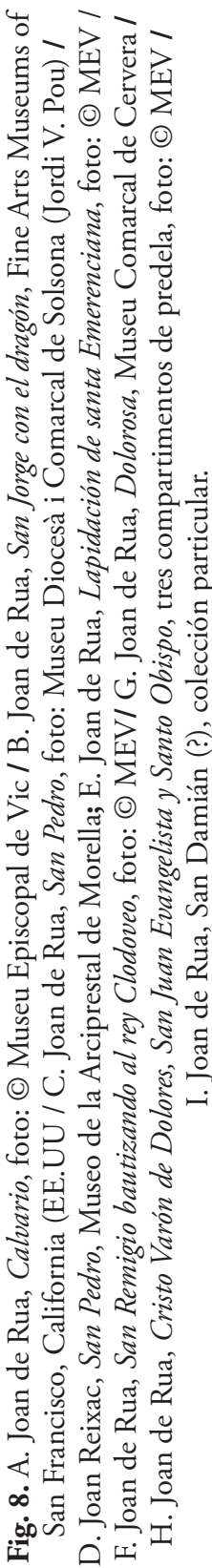




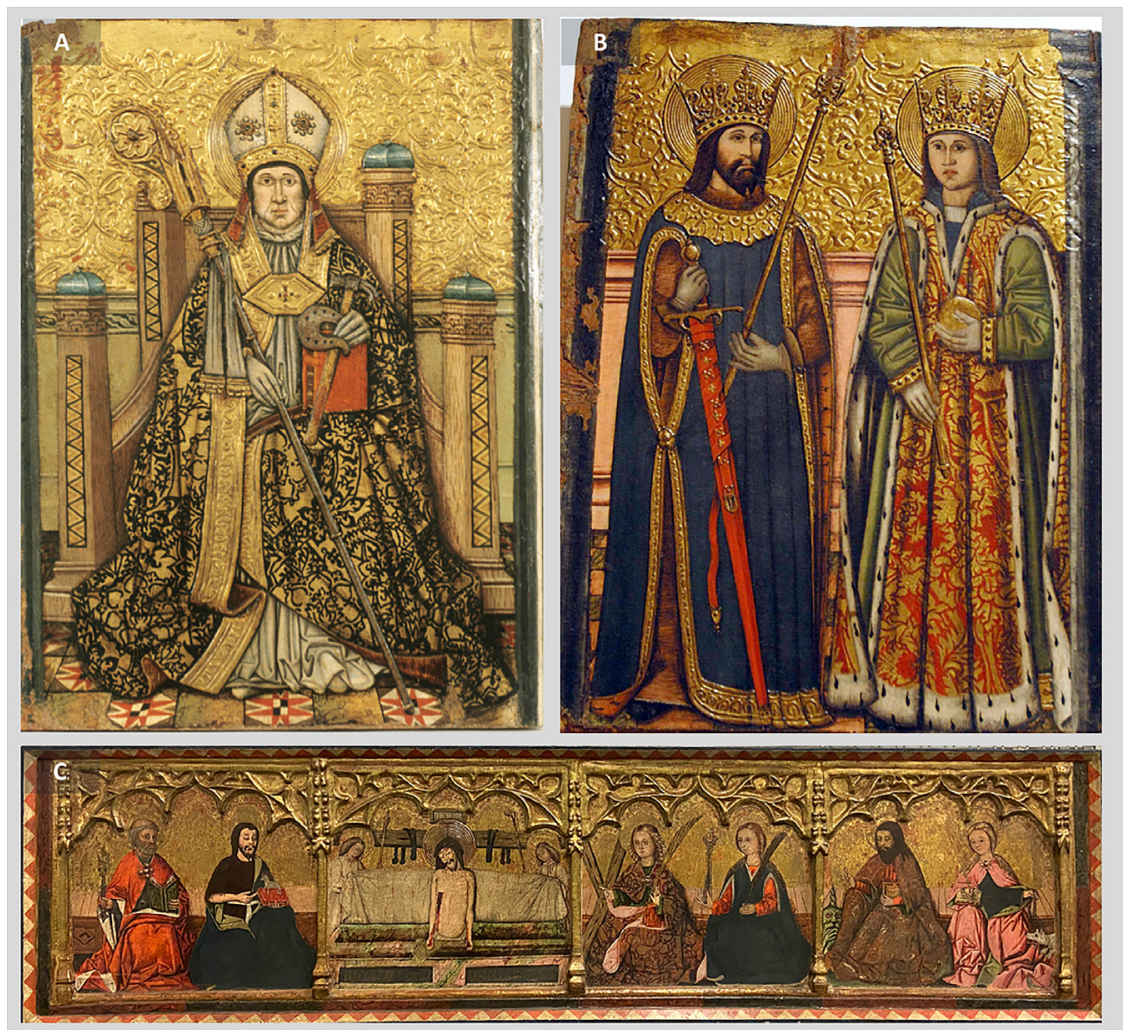

Fig. 9. Joan de Rua: A. San Eloy;

B. San Abdón y Senén, del Retablo de San Eloy y santos Abdón y Senén de la iglesia de San Miguel de Montblanch, fotos: CRBMC Carles Aymerich

(Arxiu del Museu Diocesà de Tarragona. Núms. inv. MDT-oo43 i MDT-oo44) / C. Joan de Rua, San Pedro y S. Juan Bautista, Cristo Varón de Dolores, Santa Eulalia y Santa Apolonia, Sant Bartolomé y Santa Margarita, MNAC (depositada en el Museu de Lleida) 